Research review paper

\title{
Continuous cultivation of photosynthetic microorganisms: Approaches, applications and future trends
}

\author{
Bruno D. Fernandes, Andre Mota, Jose A. Teixeira *, Antonio A. Vicente \\ CEB-Centre of Biological Engineering, University of Minho, Braga, Portugal
}

\section{A R T I C L E I N F O}

\section{Available online 14 March 2015}

\section{Keywords:}

Continuous cultivation

Photobioreactor

Microalgae

Cyanobacteria

Technical-economic assessment

\begin{abstract}
A B S T R A C T
The possibility of using photosynthetic microorganisms, such as cyanobacteria and microalgae, for converting light and carbon dioxide into valuable biochemical products has raised the need for new cost-efficient processes ensuring a constant product quality. Food, feed, biofuels, cosmetics and pharmaceutics are among the sectors that can profit from the application of photosynthetic microorganisms.

Biomass growth in a photobioreactor is a complex process influenced by multiple parameters, such as photosynthetic light capture and attenuation, nutrient uptake, photobioreactor hydrodynamics and gas-liquid mass transfer.

In order to optimize productivity while keeping a standard product quality, a permanent control of the main cultivation parameters is necessary, where the continuous cultivation has shown to be the best option. However it is of utmost importance to recognize the singularity of continuous cultivation of cyanobacteria and microalgae due to their dependence on light availability and intensity.

In this sense, this review provides comprehensive information on recent breakthroughs and possible future trends regarding technological and process improvements in continuous cultivation systems of microalgae and cyanobacteria, that will directly affect cost-effectiveness and product quality standardization. An overview of the various applications, techniques and equipment (with special emphasis on photobioreactors) in continuous cultivation of microalgae and cyanobacteria are presented. Additionally, mathematical modeling, feasibility, economics as well as the applicability of continuous cultivation into large-scale operation, are discussed.
\end{abstract}

(c) 2015 Elsevier Inc. All rights reserved.

\section{Contents}

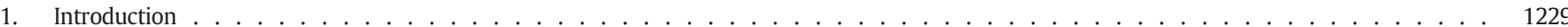

1.1. Principles of continuous cultivation . . . . . . . . . . . . . . . . . . . . . . . . . . . . . . . . . 1229

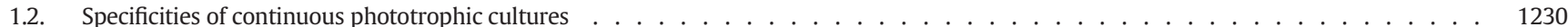

1.3. Continuous cultivation methods . . . . . . . . . . . . . . . . . . . . . . . . . . . . . . . . . . 1230

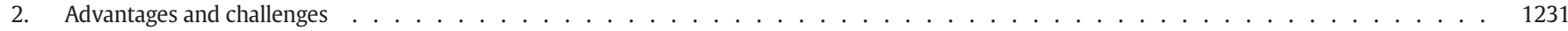

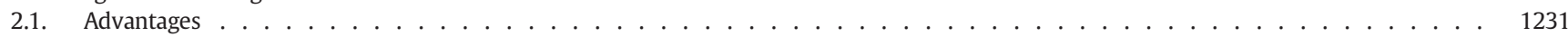

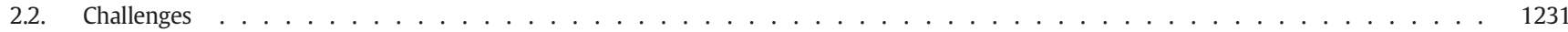

2.2.1. Strategies to overcome limitations . . . . . . . . . . . . . . . . . . . . . . . . . . . 1232

3. Equipment, operational and technical-economic assessment . . . . . . . . . . . . . . . . . . . . . . . . . . 1232

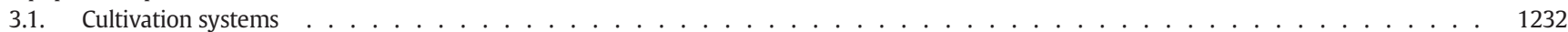

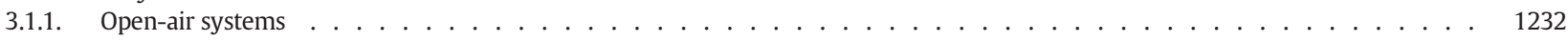

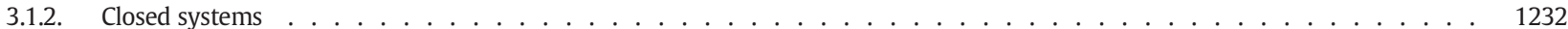

3.1.3. PBRs used in continuous mode . . . . . . . . . . . . . . . . . . . . . . . . . . . . . . . . . . 1233

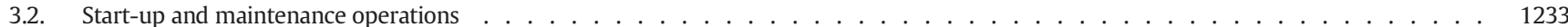

3.2.1. $\quad$ PBR cleaning and sterilization $\ldots \ldots \ldots \ldots \ldots$

3.2.2. Medium and gas sterilization . . . . . . . . . . . . . . . . . . . . . . . . . . . . . . . . . 1234

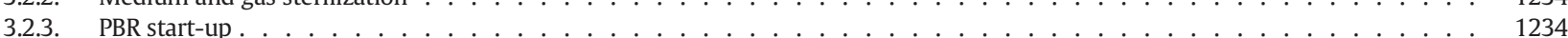

Abbreviations: PBR, Photobioreactor; EPA, Eicosapentaenoic acid; MEC, Major equipment costs

* Corresponding author.

E-mail address: jateixeira@deb.uminho.pt (J.A. Teixeira). 
3.2.4. Maintaining the continuous operation . . . . . . . . . . . . . . . . . . . . . . . . . . . . . . . . . . 1234

3.3. Monitoring and control techniques . . . . . . . . . . . . . . . . . . . . . . . . . . . . . . . . . . . . . . 1234

3.3.1. Monitoring . . . . . . . . . . . . . . . . . . . . . . . . . . . . . . . . . . . . 1235

3.3.2. Control .. . . . . . . . . . . . . . . . . . . . . . . . . . . . . . . . . . . . 1236

3.4. Downstream processes . . . . . . . . . . . . . . . . . . . . . . . . . . . . . . . . . . . 1236

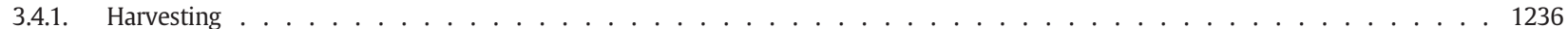

3.4.2. Biomass processing and metabolite recovery . . . . . . . . . . . . . . . . . . . . . . . . . . . . . . . . 1237

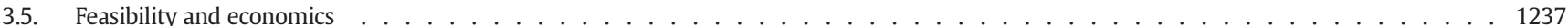

4. Applications . . . . . . . . . . . . . . . . . . . . . . . . . . . . . . . . . . . . . . . . . . . . 1239

4.1. Research tool . . . . . . . . . . . . . . . . . . . . . . . . . . . . . . . . . . . . 1239

4.2. Production strategy . . . . . . . . . . . . . . . . . . . . . . . . . . . . . . . . . . . . . . . . . 1239

4.2.1. Wastewater treatment . . . . . . . . . . . . . . . . . . . . . . . . . . . . . . . 1239

4.2.2. Feed for aquaculture . . . . . . . . . . . . . . . . . . . . . . . . . . . . . . . . . . . . . . . 1240

4.2.3. Chemicals and biofuels . . . . . . . . . . . . . . . . . . . . . . . . . . . . . . . . . . . . . . . . . . . . 1240

4.3. Performance of phototrophic cultivations-batch vs continuous . . . . . . . . . . . . . . . . . . . . . . . . . . . . . . . . . 1240

5. Conclusions and future perspectives . . . . . . . . . . . . . . . . . . . . . . . . . . . . . . . . . . . . . . . . . . . . . . . 1241

Acknowledgments ... . . . . . . . . . . . . . . . . . . . . . . . . . . . . . . . . 1241

References . . . . . . . . . . . . . . . . . . . . . . . . . . . . . . . . . . . . . . . . . . 1241

\section{Introduction}

Photosynthetic microorganisms, especially prokaryotic cyanobacteria and eukaryotic microalgae, are considered promising candidates for many potential applications ranging from direct use of biomass (e.g., aquaculture feed and food supplements), production of high-value compounds (e.g., vitamins, pigments and polyunsaturated fatty acids) and environmental applications (e.g., biofuel production, $\mathrm{CO}_{2}$ mitigation and waste water treatment) (Fernandes et al., 2013, 2014; Klok et al., 2013a; Markou and Nerantzis, 2013; Mata et al., 2010; Wijffels et al., 2013). The commercial exploitation of these photosynthetic microorganisms raises the need for reliable, efficient and costefficient processes with a constant product quality (Kwon et al., 2012).

Currently, mass production of photosynthetic microorganisms is generally based on batch cultivation systems (Camacho et al., 1990; Marchetti et al., 2012; Rusch and Christensen, 2003). However these systems' performance is still seriously hindered by factors such as low productivity, high harvesting costs due to low cell concentrations, uncertain reliability and a variable product quality (Ganuza and Izquierdo, 2007; Guedes et al., 2014; Rusch and Christensen, 2003; Wang et al., 2013). This means that batch cultivation may not be the best choice for mass production of microalgae and cyanobacteria biomass (Camacho et al., 1990).

As the need for microalgae and cyanobacteria increases, continuous production systems are attracting interest once, according to many authors, these systems are the most suitable way to achieve successful large scale production of those photosynthetic microorganisms mainly due to higher volumetric productivities, constant product quality, reduction of space requirement, decrease of labor costs, lower investment and operational costs and decrease of "unprofitable" periods (Cuaresma et al., 2009; González-López et al., 2012; Gutierrez-Wing et al., 2012; Rusch and Christensen, 2003; Sforza et al., 2014; Tang et al., 2012; Zijffers et al., 2010).

This review presents the basic principles, the main advantages and challenges, the equipment, maintenance, monitoring, control and downstream processes associated to continuous cultivation of these photosynthetic microorganisms. The feasibility and economic aspects, the main applications and the future perspectives of these systems are also addressed.

\subsection{Principles of continuous cultivation}

Despite the first references to a continuous cultivation technique report to the 1920s (Cooney, 1979) and the first continuous cultivation of photosynthetic microorganisms to the 1940s (Myers and Clark, 1944), it were the studies developed by Monod (1950) and Novick and Szilard (1950) that marked the formal initiation and application of continuous culture. However the heyday of continuous cultivations was during the 1960s, where this technique was used very often as a tool to investigate biochemical, ecological, genetic and physiological aspects of different microorganisms (Hoskisson and Hobbs, 2005). The theory presented by these authors is based in the observation that, during microorganisms' growth in batch systems, substrates are depleted and products accumulate, which at a given point makes growth to cease due to limiting substrate depletion or growth-inhibiting products accumulation. So, in order to maintain cells' proliferation, the substrate needs to be replaced and the inhibitory products to be removed in a continuous way, which is basically what happens in continuous cultivations (Lee and Shen, 2004).

Generally, continuous culture can be defined as an open system in which fresh culture medium is continuously added to the bioreactor and the culture broth (including cells and metabolites) is also continuously removed (Brethauer and Wyman, 2010; Guedes et al., 2014; Paulová et al., 2013). Usually the volume of culture broth is kept constant inside the bioreactor and the microorganisms are in a nearly unchanged environment. This forces the microorganisms to adjust their physiology and composition to the environmental conditions provided and after some generations a steady-state is usually attained (Guedes et al., 2014). In this sense, the continuous cultivation theory makes use of the relationship between the availability of the limiting substrate and microbial growth. The mass balance in a bioreactor operating in continuous mode is usually defined by:

$\mathrm{V} \cdot d C_{X} / d t=\mu C_{X} \cdot \mathrm{V}+F_{\text {in }} \cdot C_{\text {Xin }}-F_{\text {out }} \cdot C_{\text {Xout }}$

Where $\mathrm{V}$-working volume $(\mathrm{L}) ; d C_{X} / d t$-biomass accumulation inside the bioreactor $(\mathrm{g} /(\mathrm{L} \mathrm{h})) ; \mu$-specific growth rate $\left(\mathrm{h}^{-1}\right) C_{X}$-biomass concentration $(\mathrm{g} / \mathrm{L}) F_{i n}, F_{\text {out }}{ }^{\cdot}$-volumetric inflow and outflow $(\mathrm{L} / \mathrm{h})$.

Assuming: (i) constant flow $\left(F=F_{\text {in }}=F_{\text {out }}\right)$; (ii) constant volume; (iii) the steady state conditions $\left(d C_{X} / d t=0\right)$ (Lee et al., 2013) and taking in consideration the dilution rate definition $(D=F / V)$, the Eq. (1) can be simplified to:

$\mu=D$

$D$ is the reciprocal of the residence time, which is defined as the average time that a fluid element spends inside the bioreactor. Considering a constant working volume, the dilution rate can be manipulated and the continuous mode can operate at a defined (and constant) or variable dilution rate (Ferreira and Teixeira, 2003). Eq. (2) presumes that the specific death rate is negligible comparing to $\mu$, which is not always true and must be taken in account (Wood et al., 2005). 


\subsection{Specificities of continuous phototrophic cultures}

Although they may also growth under mixotrophic and heterotrophic conditions, microalgae and cyanobacteria are mainly phototrophs and almost all their cultivations are made in photoautotrophic conditions. Consequently, in this review, the continuous cultivation of photosynthetic microorganisms (cyanobacteria and microalgae) will be discussed, almost exclusively, in photoautotrophic conditions.

When compared to the continuous cultivations of other microorganisms, continuous cultivation of microalgae and cyanobacteria is a particularly complex process, because in addition to all the factors inherent to any microorganism cultivation (e.g., reactor hydrodynamics, substrate consumption and product formation), it is also necessary to take into account the extra and multiple effects of light such as photosynthetic light capture and light attenuation of the suspension (Cuaresma et al., 2011; Molina Grima et al., 1999; Sforza et al., 2014;). This is of utmost importance since it has been reported that biomass composition and productivity are greatly influenced by light quality (spectra of the energy penetrating into the culture) and quantity (total amount of energy penetrating into the culture) (Fernandes et al., 2014).

Unlike most microorganisms, in photosynthetic microorganisms the relation between $D, \mu$ and productivity $\left(\mu * C_{X}\right)$ is not straightforward. Generally in photosynthetic microorganisms maximum growth rate $\left(\mu_{\max }\right)$ is obtained at low cell densities and in the absence of lightlimited conditions. In the other hand high productivities occur at high $C_{X}$ and low or moderate $\mu$ at light-limited conditions (Richmond, 2013). In light-limited conditions it is considered that all energy is absorbed by the biomass during a defined small time-interval $(d t)$. Therefore the energy balance is given by:

$\mathrm{V} \cdot d E=I A d t-F C_{X} / Y d t$

Where $d E$-energy net increase $\left(\mathrm{J} \mathrm{L}^{-1}\right) ; \mathrm{I}$-photon flux density in the photosynthetically available range $\left(\mathrm{J} \mathrm{m}^{-2} \mathrm{~h}^{-1}\right) ; A$-illuminated surface area $\left(\mathrm{m}^{2}\right)$; and $Y$-growth yield $(\mathrm{g} / \mathrm{J})$. Considering the same conditions as in Eq. (1), Eq. (3) can be simplified to:

$D C_{X}=I A Y / \mathrm{V}$

In photobioreactors (PBRs) the productivity is controlled by availability of light, especially at higher scale of operation (Molina Grima et al., 1999). This means that considerations about the system productivity must have in account the specific microorganism growth conditions. In light-limited conditions the photosynthetic microorganisms growth is limited by the photon flux density (I), which is related with the biomass specific growth rate $(\mu)$. Generally this is done by the modification of Monod equation (Gobel, 1978; Lee et al., 2013), which assumes the following form:

$\mu=\mu_{\max } \cdot I /\left(I+K_{I}\right)$

Where $\mu_{\max }-$ maximum specific growth rate and $K_{I}$-light saturation constant.

It is important to note that Eq. (5) is only valid for light-limited conditions and not for situation where light is in excess (photo saturation). Moreover this assumptions based in Monod equation consider that temperature is kept constant in all (indoor and outdoor) continuous cultivations.

As in outdoors conditions light can vary significantly it is important to define a robust model able to predict the specific growth rate $(\mu)$ under these variable light conditions. This work has been done and reviewed by some authors (Aiba, 1982; Banister, 1979; Molina Grima et al., 1999) that considered the average light irradiance $\left(I_{A V}\right)$, which is the light experienced by a single cell randomly moving in a PBR. These models are normally very strain and PBR dependent and the approach for $I_{A V}$ determination can go from simple to more complex estimations
(Molina Grima et al., 1994, 1999). The main difficulty associated to the correlation between $\mu$ and $I_{A V}$ in continuous outdoor cultivations arise from the light variations during the day (and during the seasons of the year) and the light attenuation inside the PBRs. This can be estimated considering the Lambert-Beer law, the PBR design and the relative sun position (Molina-Grima et al., 1994).

As reported previously, an important concept in continuous cultivation of photosynthetic microorganisms is the concept of optimal cell density (OCD), which is defined as the biomass concentration that allows the highest desired product or biomass productivity (Myers and Graham, 1958; Richmond, 2013;). However, at OCD the $\mu$ is not maximal, in fact, Myers and Graham (1958) reported that at OCD the $\mu$ was about one-half $\mu_{\max }$ and four times the $\mu_{\min }$ measured in the lowest and highest cell concentrations, respectively.

For all the reasons abovementioned, monitoring and control of light regime inside the cultivation system is a central process consideration to maintain a highly productive continuous phototrophic cultivation.

The continuous outdoor production of photosynthetic microorganisms is restricted by light availability during the night period, which leads to biomass losses (due to respiration) up to 25\% (Chisti, 2007). Only the utilization of artificial lighting allows a $24 \mathrm{~h}$ continuous production, but this strategy demands a significantly higher energy input. Therefore, in general, continuous large-scale production of photosynthetic microorganisms is only performed during daylight (Chisti, 2007). Therefore,

in the present review, the cultivation mode (e.g., batch, continuous) will be defined as the one performing during the light period.

Despite the importance of the light issue, in order to obtain a high biomass/product yield and a stable product quality, a permanent control of many other independent and mutably dependent factors is required (Kwon et al., 2012).

Considering this, the continuous cultivation presents itself as a very promising, but challenging, option to mass cultivation of microalgae and cyanobacteria.

\subsection{Continuous cultivation methods}

The most common method used in continuous cultivation of microalgae and cyanobacteria is the turbidostat, being the luminostat and chemostat mainly used as research tool (Fig. 1).

In situations where: $i$ ) a constant cell density is desirable, $i i)$ there is the presence of inhibitory substrates, iii) slow growing microorganisms or with complex cell cycle are present, iv) near maximum growth rate is

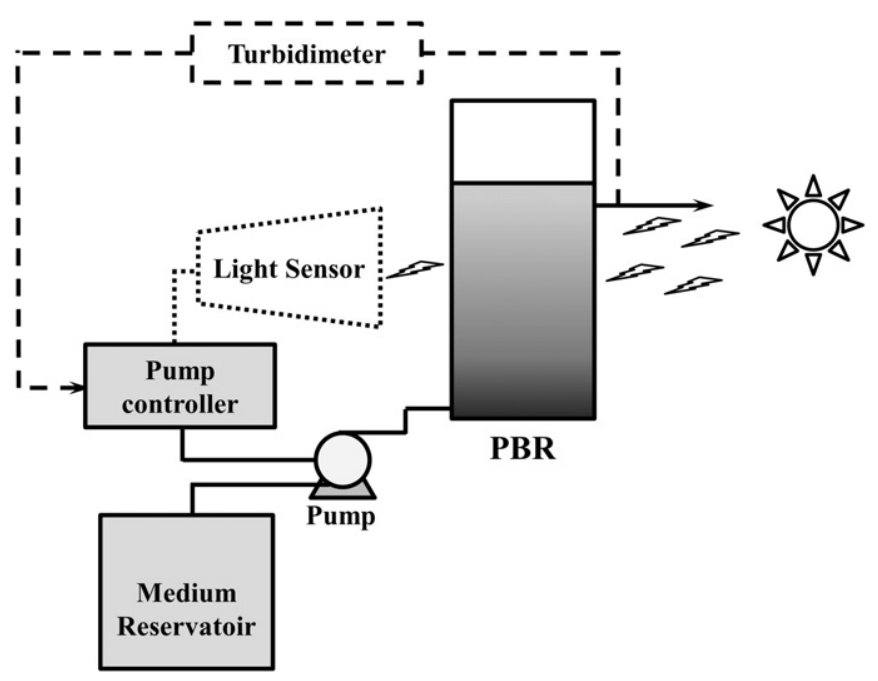

Fig. 1. Schematic representation of continuous cultivation methods. All the elements represented with continuous line refer to chemostat; continuous and dashed lines refer to turbidostat; continuous and dotted lines refer luminostat. 
attained or $v$ ) the cultures are unstable in chemostat mode, the best and most common option is to use the turbidostat approach (Lee and Shen, 2004).

A good example of this situation is the cultivation of the microalga Haematococcus lacustris, where the utilization of a fixed $D$ in chemostat results in a washout, because the $\mu$ of $H$. lacustris is not constant at the different cell cycle phases (Lee and Ding, 1994), making turbidostat the best option for continuous cultivation of these cells.

The turbidostat is quite common in continuous microalgae cultivation (James and Al-Khars, 1990; Tang et al., 2012), but it is a more complex and challenging technique than chemostat (Sandnes et al., 2006).

In turbidostat an automatic system composed by an optical sensor (for sensing the turbidity) and a pump is used to maintain the turbidity in the bioreactor (Fig. 1-elements with continuous and dashed lines). This is usually done by adjusting the feed rate of fresh medium through a feedback control loop (Lee and Shen, 2004; MacIntyre and Cullen, 2005).

In addition to turbidity, other growth-linked parameters such as $\mathrm{pH}$, substrate concentration, $\mathrm{CO}_{2}$ consumption or $\mathrm{O}_{2}$ production, can be used as alternatives to control the continuous growth (Lee and Shen, 2004).

In order to overcome continuous changes in light conditions (e.g., due to the position of the sun and changes in the weather), the luminostat (Fig. 1-elements with continuous and dotted lines) has been proposed. In a luminostat the biomass concentration is constantly adapted to the light conditions in order to maximize light absorption and reducing dark volumes, which results in maximal productivity (Richmond, 2013). In this approach the light transmission is controlled by measuring the light intensity at the rear of the PBR (Cuaresma et al., 2011; Takache et al., 2010). The utilization of luminostat technique reduce the effects of photosaturation and photolimitation, increasing the photosynthetic efficiency and productivity (Cuaresma et al., 2011).

In chemostat cultures (Fig. 1-elements with continuous lines), the limiting nutrient present in fresh medium is fed into the PBR at a predetermined and fixed $D$, which according to Eq. (2) will determine $\mu$. Due to its capacity to control $\mu$ and maintain an environment with a constant chemical composition that forces the adjustment of cells' physiology, chemostat operation is widely used as a research tool to study, for example, the effects of substrate concentration, $\mathrm{pH}$ or temperature at constant specific growth rates (Grima et al., 1994; Hoskisson and Hobbs, 2005; Iehana, 1983; Klok et al., 2013a; Lee and Shen, 2004; Lee and Soh, 1991; Pirt et al., 1980).

Other methods for continuous cultivations of photosynthetic microorganisms are also proposed in the literature. Barbosa et al. (2005) proposed the acceleration-stat (A-stat) technique in which the biomass productivity of the microalgae Dunaliella tertiolecta was optimized by continuously changing of the dilution rate at a constant acceleration rate. Rhee et al. (1981) proposed a cyclostat approach, in which cells are subjected to alternating light and dark periods. The utilization of continuous cultivation methods, other than turbidostat, is almost restricted to laboratory use.

\section{Advantages and challenges}

\subsection{Advantages}

Due to a particular set of features, the continuous cultivation of photosynthetic microorganisms is, in many situations, a very attractive alternative to the widely used batch cultures. In batch cultures the cell composition can vary during time as cells get older and the bulk environment changes. Oppositely, in continuous cultures the efficient control of growing environment allows to obtain a tailor-made biomass composition at a constant and predetermined rate (Borowitzka, 1997; Clarkson et al., 2001; Klok et al., 2013a; Palmer et al., 1975; Zhu and Jiang, 2008). Considering the fact that irradiance, salinity or specific nutrients concentration (e.g., phosphorus or nitrogen) can determine cell composition, it is possible to consistently obtain a product with reasonably stable characteristics by, for example, keeping a constant nutrient concentration or cell density (Dragone et al., 2011; Fernandes et al., 2013; Hu, 2004; Marchetti et al., 2012; Tzovenis et al., 2003). Another strategy to influence the cell composition is through the manipulation of average cell age. It is known that in different stages of their growth, microalgal and cyanobacterial cells have different compositions (Alonso et al., 2000) and being $D$ the reciprocal of the residence time, its value will determine the age of cells present in the PBR. Another major advantage is the fact that growth and photosynthetic rates can be maintained near their maximum value (at low cell densities), which is of utmost importance when the objective is the efficient production of growth-associated products (Agrawal et al., 1989; Posten, 2009; Wang et al., 2013).

In opposition to batch systems, in continuous cultivation cell density can be maintained around $O C D$, which results in maximal biomass productivity. At OCD the effect of light attenuation is overcome by number of additional catalytic units (Richmond, 2013).

It has been previously reported and described (Fernández et al., 2012; Fernández-Sevilla et al., 2014; Lee et al., 2013; Mata et al., 2010) that, theoretically, and without considering the time needed to clean and re-start a batch culture, the productivity in continuous cultivation systems is 2.3 to 5 times higher than in batch mode. Moreover, this operation mode enables the achievement of high cell densities, which besides obtaining higher productivities also allow reducing harvesting costs since continuous harvesting (e.g., continuous centrifugation) is much more efficient than the intermittent processing of large volumes from a batch cultivation (Borowitzka, 1999; Ganuza and Izquierdo, 2007; Zhu and Jiang, 2008). The fact that product harvesting can take place during cultivation makes the continuous systems particularly suitable for processes where the production of extracellular compounds, volatile products or autoinhibiting compounds are mainly targeted (Lindberg et al., 2010; Niederholtmeyer et al., 2010; Sharma and Stal, 2014). Continuous processes might be also the only viable option in situations where it is necessary to operate with toxic (e.g., removal of toxic pollutants from wastewaters) or low solubility substrates.

Other characteristics such as: reduction of space requirement due to smaller equipment; decrease of labor costs due to a full automation of the production process; lower investment and operational costs; decrease of "unprofitable" periods of bioreactor operation due to a reduction in the downtime for cleaning and sterilization; suppression of water loss by evaporation; and the opportunity to decrease the viscosity of the broth whenever necessary, make continuous cultivation a very appealing strategy for commercial or lab scale cultivation of microalgae and cyanobacteria (Borowitzka, 1999; Brethauer and Wyman, 2010; Kwon et al., 2012; Marchetti et al., 2012; Paulová et al., 2013; Sharma and Stal, 2014; Zhu and Jiang, 2008).

\subsection{Challenges}

Despite the mentioned advantages of continuous systems, batch cultivation is the most common method used in the cultivation of microalgae and cyanobacteria (Bougaran et al., 2003; Guedes et al., 2014; Loubière et al., 2009; Marchetti et al., 2012; Qiu 2010). The reasons for this preference are similar to those in other industries, like the brewing industry, where, despite the evident advantages of continuous systems, batch systems are still preferred (Brányik et al., 2006, 2012; Pires et al., 2014). The typically presented motives have its source in "emotional" and techno-economic bases. The former are represented by a resistance to change, mistrust caused by the lack of information and the accommodation to the already implemented batch processes. The main techno-economic reasons that contribute to this reluctance are: the system complexity and therefore the necessary skilled labor for maintenance and operation (Eriksen et al., 1998; Sharma and Stal, 2014); the need of special equipment; and a higher contamination potential, which is the result of a much longer time of operation (in the range of months) 
with a continuous pumping of the medium (Muñoz and Guieysse, 2006; Paulová et al., 2013; Rusch and Christensen, 2003). Regarding the contamination risk, it is important to emphasize that the potential for culture collapse due to inadvertent contaminants is not an exclusive phenomenon of continuous cultivations, and does also occur in batch cultures (Rusch and Christensen, 2003). Other limitations such as the inability to provide constant natural illumination, which can restrict continuous systems to indoors; microbial attachment to walls during long cultivation periods (thus hampering light penetration); and the possibility of spontaneous genetic mutations in the microbial strains in a long-term operation, are also referred as limitations of continuous systems (Eriksen et al., 1998; Loubière et al., 2009; Marchetti et al., 2012; Paulová et al., 2013; Sharma and Stal, 2014; Tsygankov et al., 1998).

\subsubsection{Strategies to overcome limitations}

Several strategies have been developed in order to overcome some of the constraints addressed to continuous cultivation of photosynthetic microorganisms. In order to control the contamination or, when possible, reduce its risk, different techniques have been tested and described in the literature. Among these strategies the use of an in situ net in order to control the contamination by insects, leaves or other airborne material have been proposed by Borowitzka (2005) to be used in open-air systems. The preference for closed PBRs and the utilization of highly selective growth conditions (e.g., extreme salinities, high nutrient concentration, high $\mathrm{pH}$ ) have been proposed as strategies to avoid and control the contamination with microorganisms (Borowitzka, 1991; Post et al., 1983; Vonshak, 1990).

As previously demonstrated, another inherent limitation of continuous cultivation is the deposition of cells in the reactor walls. To prevent this situation several approaches, e.g., introduction of turbulence or scraping, have been tested and described in the literature. More information about strategies control of contamination and cell wall growth is presented in Section 3.2.4.

To increase the process cost-effectiveness is vital to reduce the construction and operation costs of continuous cultivation systems. However, this reduction should not be done at the expense of productivity, purity and quality of the culture. The balance between costs and product quality can be achieved by, for example, the utilization of cheap materials in the construction of the PBRs (Tredici, 1999) and the full automation of the process (Marchetti et al., 2012). The utilization of downstream processes operating in continuous mode (e.g., harvesting, cell rupture and product extraction) should be fully explored and optimized, since it allows a real-time monitoring and control of the process, increasing the productivity and decreasing the investment, which are important economic advantages over typical batch processes (Jungbauer, 2013). Other strategies to decrease the production costs in continuous systems are discussed in detail in Section 3.5.

To overcome some of existing resistance to the implementation of continuous cultivation it is necessary to provide representative case studies where the advantages of continuous cultivation are clearly demonstrated and combined with a rigorous and realistic techno-economic assessment. Also, the emergence of successful continuous cultivation projects like the Aquasearch facility, located in Hawaii that tested the continuous-wise production of astaxanthin by Haematococcus pluvialis in outdoor enclosed $25 \mathrm{~m}^{3}$ tubular photobioreactors (Guedes et al., 2011), can be a decisive driving force.

\section{Equipment, operational and technical-economic assessment}

Implementing a continuous cultivation requires certain procedures, techniques and the acquisition of specific equipment, in order to take full advantage of its potential.

In continuous cultures, it is crucial to know in advance the behavior of the desired microorganism under the selected operation conditions. Therefore, a number of small batch cultivations should be performed before starting the continuous cultivations, in order to collect information about the best growth conditions (e.g., light, temperature, $\mathrm{pH}$, growth medium and $\mathrm{CO}_{2}$ concentration), the different growth phases and their relation with the product (e.g., if is a growth associated product or not), the presence of eventual inhibitors and to determine which is the limiting substrate (among other case-specific information). The basic equipment required for continuous cultivation of microalgae and cyanobacteria is generically represented by a PBR, complemented by specific equipment for continuous preparation and sterilization of medium (when required), pumps to deliver the medium (and eventually withdraw the broth), aeration system, monitoring sensors, controllers and equipment for downstream processing.

\subsection{Cultivation systems}

Firstly, it is important to stress that all the existing cultivation systems are, occasionally with minor modifications, suitable for continuous operation. Therefore, in this chapter a general approach to PBRs (in this text the term photobioreactor is used for both open-air and closed systems) will be made (this subject has been extensively reviewed by (Borowitzka, 1999; Tredici, 2004; Mata et al., 2010; Posten, 2009; Dragone et al., 2010; Wang et al., 2012), followed by a mention to specific applications of PBRs in continuous phototrophic cultivations. The PBR selection is one of the most crucial steps to define the feasibility of commercial production of photosynthetic microorganisms since its selection will influence construction and maintenance costs, system productivity and the risk of contamination. It will also significantly influence biomass composition and will determine, for example, the occurrence of photoinhibition and photooxidation, the light-dark cycle frequency, the cells' light history, and the possible accumulation of toxic levels of oxygen in the culture (Fernandes et al., 2014; Mirón et al., 2003).

\subsubsection{Open-air systems}

Typical open-air PBRs include lakes and natural ponds, circular ponds, raceway ponds and inclined systems. These PBRs have been extensively studied in the past few years (Borowitzka, 1999; Chaumont, 1993; Dragone et al., 2010; Tredici, 2004) and they are the most widespread systems for the mass cultivation of microalgae (e.g., Dunaliella, Chlorella) and cyanobacteria (e.g., Spirulina), representing all very large commercial systems being used (Abdulqader et al., 2000; Dragone et al., 2010; Spolaore et al., 2006; Thein, 1993; Tredici, 2004). The dissemination of these open-air systems is mostly due to operational and economic factors, since they are easier and less expensive to build and have a larger production capacity than most closed systems (Carlsson, 2007; Dragone et al., 2010; Tredici, 2004). Although these systems are the most widely used at industrial level, they still present significant technical challenges such as low biomass concentration and productivity. They are also very susceptible to contamination and to meteorological conditions, especially fluctuations in nutrient and cell concentrations due to evaporation and rain (Dragone et al., 2010; Tredici, 2004). Therefore, the utilization of these PBRs is currently restricted to fast growing, naturally occurring or extremophilic species like Dunaliella (adaptable to very high salinity), Spirulina (adaptable to high alkalinity) and Chlorella (adaptable to nutrient-rich media) (Carlsson, 2007). Due to the high risk of contamination, combined to extreme difficulty to control main variables such as biomass concentration, temperature, $\mathrm{pH}$ and oxygen content, open-air systems are not considered very appropriate for continuous cultivation (Muller-feuga et al., 1998).

\subsubsection{Closed systems}

In opposition to open-air systems, closed systems allow regulating and controlling nearly all the biotechnological parameters while reducing contamination risks, $\mathrm{CO}_{2}$ losses and water evaporation. It is also easier to obtain reproducible cultivation conditions, controllable hydrodynamics and a more stable operation temperature (Pulz et al., 2001). Closed 
PBRs are more flexible and can be placed outdoor or indoor depending on the product of interest, production level and local weather conditions. In recent years research in closed PBRs has increased due to the new microorganisms of interest and high-value products for use in the pharmaceutical and cosmetics industry that, imperatively, must grow free of contaminants (Dragone et al., 2010). Many different designs have been developed, and the main categories include: $i$ ) tubular; ii) flat; and iii) column PBRs. The largest closed PBRs are tubular, like the $25 \mathrm{~m}^{3}$ plant at Mera Pharmaceuticals, Hawaii, and the $700 \mathrm{~m}^{3}$ plant in Klötze, Germany (Brennan and Owende, 2013; Dragone et al., 2010; Olaizola, 2000). These PBR systems are relatively cheap, have a large illumination surface area and have quite good biomass productivities. Flat PBRs have a large surface area exposed to illumination and high densities $\left(>80 \mathrm{~g} \mathrm{~L}^{-1}\right)$ of photoautotrophic cells were observed (Brennan and Owende, 2010). Column PBRs are frequently low-cost, compact and easy to operate. Additionally they usually provide the most efficient mixing, the highest volumetric gas transfer rates, and the best controllable growth conditions (Tredici, 2004). Comprehensive reviews with detailed description, advantages and disadvantages and comparison of each closed PBR category can be found elsewhere (Carvalho et al., 2006; Chaumont, 1993; Dragone et al., 2010; Janssen et al., 2003; Kunjapur and Eldridge, 2010; Posten, 2009; Tredici, 2004).

\subsubsection{PBRs used in continuous mode}

Despite the fact that all the previously described PBRs have been, or at least are suitable to be, used in continuous mode, most of continuous systems are implemented in closed PBRs in order to minimize contamination and increase systems' control (Rusch and Christensen, 2003). In the last years many PBRs have been tested for the continuous cultivation of microalgae and cyanobacteria (Table 1 ). The productivity and effectiveness of each PBR varies between studies since these parameters depend on the microorganism and the selected operational conditions. In Table 1 are only considered studies in which PBRs with significant volumes ( $>50 \mathrm{~L}$ ) were tested. Through an intensive analysis of literature it is possible to conclude that the selection of the PBR to be used in continuous cultivation (as in batch) will be the result of a detailed integrated analysis of different elements such as: $i$ ) market value and required characteristics for the product of interest; ii) selected microorganism; iii) contamination risk; iv) local weather conditions; $v$ ) cultivation medium used; and vi) land availability. The systems used in laboratory research tend to be more sophisticated, since axenic conditions and more complex and accurate control is required (Droop, 1966; Hoskisson and Hobbs, 2005).

In some situations of pollutants removal from wastewater, production of an extracellular metabolite or for the maintenance of high cell densities inside the PBR, microalgal and cyanobacterial cells are immobilized by adsorption to solid surfaces, mostly with the aim of improving the performance of the system (De-Bashan et al., 2002; Pradhan and Rai, 2000). The main issues in photosynthetic cells immobilization are: $i$ ) the aggressiveness of some immobilization processes (Garbisu et al., 1991); ii) the low nutrient availability and light limitation due to the presence of a carrier (Moreno-Garrido, 2008); and iii) price and mechanical performance of matrices (Muñoz and Guieysse, 2006). More information about current immobilization techniques, carriers and physiological effects on photosynthetic cells due to immobilization can be found in an excellent review by Moreno-Garrido (2008).

\subsection{Start-up and maintenance operations}

In order to operate a PBR in continuous mode there are several auxiliary operations that need to be completed before reaching the full continuous operation. In general, it is important to define an easy and quick start-up operation, keep sterile conditions to avoid contaminations and avoid cell wall deposition. Continuous operation generically involves the following steps: $i$ ) PBR cleaning and sterilization; ii) medium and air sterilization; iii) PBR start-up; and iv) maintaining the continuous operation.

\subsubsection{PBR cleaning and sterilization}

Depending on the PBR construction material (optically clear materials like glass, acrylic, polyethylene or polyvinyl chloride), scale (laboratory, pilot or industrial) and growth medium contamination risk (e.g., highly selective, non-selective medium or wastewater), different procedures of sanitation or sterilization can be adopted. Techniques such as steam sterilization and autoclave are not suitable for the sterilization of most of the PBRs due to the kind of materials used and/or their size (Behrens, 2005). The autoclave is used for PBRs with volumes up to $10 \mathrm{~L}$ (Castellanos, 2013; Javanmardian and Palsson, 1992) and the in situ heat sterilization for volumes between $10 \mathrm{~L}$ and $100 \mathrm{~L}$ (Fonseca and Teixeira, 2007). A different alternative is the sterilization by ozonation, however these systems tend to be expensive (Quesnel, 1987). Sanitation, using hypochlorite solution (Behrens, 2005) or peroxyacetic acid solution (Loubière et al.,

Table 1

PBRs used for continuous cultivation of photosynthetic microorganisms.

\begin{tabular}{|c|c|c|c|c|}
\hline PBR & Microorganism & Volume (L) & Biomass productivity $\left(\mathrm{g} \mathrm{L}^{-1} \mathrm{~d}^{-1}\right)$ & Reference \\
\hline \multirow[t]{2}{*}{ Flat panel } & Nanochloropsis & 440 & 0.27 & Cheng-Wu et al. (2001) \\
\hline & Spirulina maxima & $4 \times 64$ & 1.7 & Samson and Leduy (1985) \\
\hline \multirow[t]{4}{*}{ Tubular: fence, helical type, double layer tubes. } & Phaeodactylum tricornutum & 200 & 1.9 & Molina Grima et al. (2001) \\
\hline & Scenedesmus almeriensis & $10 \times 3000$ & $0.3-0.7$ & Acién et al. (2012) \\
\hline & Phaeodactylum tricornutum & 75 & 1.4 & Hall et al. (2003) \\
\hline & Porphyridium cruentum & 7000 & $0.29-0.36$ & Chaumont et al. (1988) \\
\hline \multirow[t]{2}{*}{ Polyethylene sleeves } & Porphyridium sp. & $10-70$ & 0.18 & Cohen et al. (1991) \\
\hline & Tetraselmis suecica & 50 & - & Trotta $(1981)$ \\
\hline \multirow[t]{3}{*}{ Bubble column } & Phaeodactylum tricornutum & 60 & 0.3 & Mirón et al. (2003) \\
\hline & Chlorella & 200 & $0.10-0.26$ & James and Al-Khars (1990) \\
\hline & Nannochloropsis & 200 & $0.032-0.095$ & James and Al-Khars (1990) \\
\hline \multirow{4}{*}{ Airlift: split cylinder and draft tube. } & Haematococcus pluvialis & 50 & 0.7 & García-Malea et al. (2009) \\
\hline & Spirulina platensis & 77 & - & Morist et al. (2001) \\
\hline & Spirulina platensis & 77 & 0.3 & Vernerey et al. (2001) \\
\hline & Phaeodactylum tricornutum & 60 & 0.3 & Mirón et al. (2003) \\
\hline \multirow[t]{5}{*}{ Hybrid: tubular + airlift } & Phaeodactylum tricornutum & 200 & 1.2 & Fernández et al. (2001) \\
\hline & Phaeodactylum tricornutum & $50-220$ & $0.50-2.74$ & Fernandez et al. (1998) \\
\hline & Muriellopsis sp. & 55 & $40^{\mathrm{a}}$ & Del Campo et al. (2001) \\
\hline & Porphyridium cruentum & 220 & 1.76 & Rebolloso Fuentes et al. (1999) \\
\hline & Porphyridium purpureum & 50 & - & Baquerisse et al. (1999) \\
\hline
\end{tabular}

a $\mathrm{g} \mathrm{m}^{-2}$ day $^{-1}$ 
2009) is a more practical and feasible solution. The information available in the literature regarding PBRs sanitation/sterilization procedures is rather scarce. In some cases it can be considered that no sterilization procedures were used, as reported in a number of situations (Reis et al., 1996). In fact sometimes sterilization is not necessary because the cultivation conditions (high salinity and/or high $\mathrm{pH}$ ) are selective enough to keep the aseptic conditions (Borowitzka, 1991; Post et al., 1983; Vonshak, 1990).

\subsubsection{Medium and gas sterilization}

In continuous cultivations, besides the sterilization of the PBR, it is also important to sterilize the gas (mixture of air and $\mathrm{CO}_{2}$ ) and medium once these are being continuously fed into the PBR. Usually gas is sterilized by filtration (Alonso et al., 2000; Camacho et al., 1990), while the medium sterilization is done by one of the following methods: autoclaving (Jácome-Pilco et al., 2009; Palmer et al., 1975), filtration (Alonso et al., 2000; Camacho et al., 1990; Fernandez et al., 2014; Sananurak et al., 2009), UV (Sananurak et al., 2009) and ozonation (Fernandez et al., 2014; Sananurak et al., 2009). It is common to use two or three methods for medium sterilization in order to guarantee aseptic cultivation conditions (Fernandez et al., 2014; Sananurak et al., 2009). At pilot and industrial scales UV and ozonation are the most common techniques (Fernandez et al., 2014; Molina Grima et al., 2003; Sananurak et al., 2009). All the auxiliary equipment like analysers or pumps can be kept free of contaminant microorganisms by the utilization of prefilters (Behrens, 2005).

\subsubsection{PBR start-up}

After the cleaning and sterilization procedures have been applied, the next step is the PBR's start-up. The most common start-up strategy is the implementation of a preliminary batch culture in order to obtain sufficient cell density (Alonso et al., 2000; Bougaran et al., 2003; D'Souza and Kelly, 2000). The alternative method is the application of the continuous regime immediately after inoculation, which allows a full automation of the process from the beginning. Bougaran et al. (2003) compared these two methods in the continuous cultivation of Isochrysis galbana affinis Tahiti and they concluded that, in both, the characteristics obtained in the steady-state were very similar.

\subsubsection{Maintaining the continuous operation}

After reaching steady-state, it is important to guarantee that the conditions are kept stable in order to preserve this state, which implies the monitoring and control of the continuous culture (for more information please see Section 3.3), the equipment maintenance, the conservation of aseptic conditions and prevent a significant cell wall growth/deposition.

Regarding to equipment maintenance, the continuous utilization leads to the necessity to clean, calibrate or replace some of the equipment during the operation. As an example, Lee (1995) stated that sensor failure is one of the most common causes to false alarms in automated system. The cell adhesion to the surface of the optical cell used in turbidostat cultivations is a very typical problem that could limit the normal operation of a continuous cultivation (Lee and Shen, 2004). This requires a periodical cleaning process during the cultivation.

3.2.4.1. Dealing with contamination during continuous operation. For keeping the aseptic conditions it is important to do the maintenance of filtration and ozonation systems used for sterilize gas and medium. In open ponds sometimes a physical barrier (netting) is important to avoid contamination from unwanted living organisms and other airborne material (Borowitzka, 2005; Rosenberg et al., 2011).

When a relevant contamination is detected two main options are possible: $i$ ) application of a technique for continuous removal of the contaminant organism and ii) the end of continuous cultivation for cleaning and sterilization. As the second option is the last resource, it is important to focus on the main techniques to reduce or eliminate the contamination in continuous microalgae and cyanobacteria cultivation systems. A typical strategy to mitigate microbial contaminants is the manipulation of the dilution rate, which can result for example in light or nutrient limitation, and ultimately result in the predominance of the desired microorganism. The manipulation of other variables such as $\mathrm{pH}$, temperature or salinity can also promote the growth of the desired microorganism over the contaminant. For example, knowing that different cells present different sensitivities to $\mathrm{NH}_{3}$, Richmond et al. (1982) minimized the contamination of Spirulina cultures with green algae by maintaining the bicarbonate concentrations above $0.2 \mathrm{M}$, the $\mathrm{pH}$ above 10 and operating at high cell densities. Also Borowitzka (2005) referred the introduction of repeated pulses of 1-2 $\mathrm{mM} \mathrm{NH}_{3}$, followed by a $30 \%$ dilution of the culture as strategy to avoid the simultaneous growth of Spirulina and Chlorella cells. Other strategies to control contamination are reported in the literature. Using the combined effect of crossflow-microscreening and a short hydraulic time (in order to wash freely suspended cells) Wood (1987) was able to recover the predominance of a Stigeoclonium strain. Fabregas et al. (1986) revealed that temperatures below $15^{\circ} \mathrm{C}$ can be used as solution to set the predominance of Euglena and Scenedesmus over Chlorella species. The manipulation of organic loads can also be used to control contaminations since different species have different tolerance to this parameter. For instance, Scenedesmus dominate at medium organic loads whereas Chlamydomonas and Euglena are the most abundant species at high organic loads (Martinez Sancho et al., 1993).

3.2.4.2. Strategies to limit cell wall growth. Microalgae/cyanobacteria cell wall growth is one of the major problems in microalgae and cyanobacteria cultivations because it will limit the penetration of light and therefore the photosynthetic rate (Béchet et al., 2013). The main techniques used to overcome this phenomenon are related to the PBRs design. The PBR design should promote, for example, a swirling flow, which will increase the shear stress near the wall decreasing cell wall growth/deposition (Loubière et al., 2009). Another approach is the use of high liquid velocities, as can be found in the BIOCOIL PBR. The main disadvantage of such strategies is the fact that high shear stresses are not suitable for all photosynthetic microorganisms (Borowitzka, 1999). Operation strategies like sporadic vigorous swirling in the form of mechanical agitation (Brewer and Goldman, 1976) or compressed air (Mock and Murphy, 1970), periodic draining, cleaning and refilling the reactor (MacIntyre and Cullen, 2005) or even manual scraping (Dunstan and Menzel, 1971) can prevent growth on the side walls of the PBR. Anderson and Brune (1982) presented a system called Scouring Film Reactor in which a continuously scouring film of glass particles avoids microalgal cell growth and settling. Also Chaumont et al. (1992)developed and patented a system to continuously clean the inner surface of their tubular PBR using recycling balls. Tsygankov et al. (1998) described a system where balls of polyurethane foam were introduced into the PBR, and they continuously scrub the PBR walls due to its continuous circulation along the PBR. Broneske et al. (2007) patented a method that involves applying ultrasonic power over the outside surface of PBRs by means of a sonotrode in order to remove the biofilm.

\subsection{Monitoring and control techniques}

Monitoring and control techniques are important in all the microbial cultivation processes, but they are imperative when the continuous mode is used, due to the necessity to maintain constant cultivation conditions. Microalgae and cyanobacteria cultivation presents additional difficulties to the monitoring and control process, due to its larger scale (increasing the difficulties in mixing and contamination control) and the fact that the desired product is frequently intracellular (Havlik et al., 2013a, 2013b). From an economic point of view, the application of automatic monitoring and control systems will not only reduce the operational costs by reducing labor impact and the amount of effluents, but will also improve the product quality (Lee, 1995; Sandnes et al., 
2006), allowing also the stable operation for long periods (in the range of months) at minimum costs.

\subsubsection{Monitoring}

Monitoring the process parameters is usually performed by sensors connected to data acquisition systems, which can be adapted from other bioprocesses that are commercially available (Moreno et al. 1998) or developed from scratch (Fernandez et al., 2014; Lee, 1995; Sandnes et al., 2006).

Monitoring of microalgae and cyanobacteria cultivations have been extensively studied and reviewed by (Havlik et al., 2013a, 2013b). These authors divided the main parameters used to monitor the cultivation of photosynthetic microorganisms in three classes (Table 2): physical (light, temperature, mixing), chemical (dissolved $\mathrm{CO}_{2}$ and oxygen, $\mathrm{pH}$ nutrient and product concentration) and biological (biomass composition, cell morphology, physiological state and photosynthetic efficiency).

Monitoring these parameters allows not only to determine important cultivation parameters such as growth rate, photosynthetic performance (Havlik et al., 2013a, 2013b), but also to develop biomass growth and composition models essential for monitoring, control and for metabolic, physiological or ecological characterization (Ifrim et al., 2014; J. Li et al., 2011; Klok et al., 2013b; Mairet et al., 2011; Su et al., 2003; Y. Li et al., 2011) . The monitoring of biological and physicochemical variables should ideally be performed in situ and on-line, however due to specificities and limitations associated to some techniques, off-line monitoring is still very common (Table 2) despite the fact that is a complex and time demanding approach (Alonso et al., 2000; Gouveia et al., 2009; Moreno et al., 1998; Pistorius et al., 2009).

Other approach for on-line monitoring of biomass properties (concentration and composition), growth rate, photosynthetic efficiency and yield is the use of software sensors (Briassoulis et al., 2010; Córdoba-Matson et al., 2009; Ifrim et al., 2014; Jung and Lee, 2006; Li et al., 2003; Su et al., 2003).
3.3.1.1. Software sensors for on-line monitoring. In real situations, continuous, on-line and direct monitoring of certain compounds (e.g., intracellular product) or biomass properties is not practical or, sometimes, even possible. To overcome this problem, discrete measurements coupled with mathematical models (or estimators) that describe the bioprocess can be used (Goffaux et al., 2009). Alternatively, the mathematical models can be associated with an indirect parameter (e.g., $\mathrm{pH}$, dissolved $\mathrm{O}_{2}$ or irradiance) that is directly related to different aspects of the bioprocess. The main advantage of this approach is that such parameters are measured with a higher frequency, avoiding discrete measurements and allowing an indirect monitoring and control (Ifrim et al., 2014; Li et al., 2003; Su et al., 2003). This strategy of coupling sensors and mathematical models is very common in many bioprocesses and is called software sensor (Havlik et al., 2013a, 2013b; Sundström, 2007). The mathematical growth models of photosynthetic microorganisms are more complex, since they have to consider not only the modeling of the main growth kinetic parameters (as in the case of other microorganisms), but also the light issues (e.g., light attenuation, photolimitation and photosaturation). The two main approaches for modeling the photosynthetic microorganisms growth are based in a modified Monod equation (Baquerisse et al., 1999; Becerra-Celis et al., 2008) or in the Droop model (Droop, 1968; Mairet et al., 2011; Toroghi et al., 2013). The majority of the software sensors developed for photosynthetic microorganisms are for the estimation of biomass concentration (Havlik et al., 2013a, 2013b) using models that relate the biomass concentration with different parameters such as: $\mathrm{pH}$ (Berenguel et al., 2004; Ifrim et al., 2014), dissolved oxygen (Li et al., 2003), local irradiance (Su et al., 2003), solar irradiation (Quinn et al., 2011) and image analysis (Córdoba-Matson et al., 2009; Jung and Lee, 2006). Due to their complexity and multi parameter influence, mathematical models that incorporate the estimation of biomass composition are less common, and are usually applied in situations where specific nutritional conditions are set (Klok et al., 2013a, 2013b; Mairet et al., 2011; Quinn et al., 2011).

Table 2

Microalgae and cyanobacteria monitoring equipment and methods (adapted from Havlik et al. (2013a)).

\begin{tabular}{|c|c|c|c|}
\hline \multirow[t]{2}{*}{ Parameter } & \multicolumn{2}{|l|}{ Monitoring method } & \multirow[t]{2}{*}{ Reference $^{\mathrm{a}}$} \\
\hline & Sensor/technique & Off-line/online & \\
\hline $\mathrm{pH}$ & $\mathrm{pH}$ meter & On-line & $(1-10)^{\mathrm{c}},(11-13)^{\mathrm{fb}},(8,11,14-17)^{\mathrm{b}}$ \\
\hline \multirow[t]{2}{*}{ Photon flux density } & Quantum sensor & On-line & $(2,6)^{\mathrm{c}},(13,18)^{\mathrm{fb}},(15,16,19-21)^{\mathrm{b}}$ \\
\hline & Fiber optic & On-line & $(22)^{\mathrm{b}}$ \\
\hline \multirow[t]{2}{*}{$\mathrm{O}_{2}$} & $\mathrm{O}_{2}$ probe & On-line & $(6,10)^{\mathrm{c}},(15,16,23)^{\mathrm{b}}$ \\
\hline & $\mathrm{O}_{2}$ analyzer & On-line & $(6,10)^{\mathrm{c}},(13,18)^{\mathrm{fb}},(23)^{\mathrm{b}}$ \\
\hline \multirow[t]{2}{*}{$\mathrm{CO}_{2}$} & $\mathrm{CO}_{2}$ probe & On-line & $(12,13,17,18)^{\mathrm{fb}},(23)^{\mathrm{b}}$ \\
\hline & $\mathrm{CO}_{2}$ analyzer & On-line & $(6,24)^{\mathrm{c}},(12,13,18)^{\mathrm{fb}},(17,23,24)^{\mathrm{b}}$ \\
\hline \multirow[t]{7}{*}{ Biomass concentration } & Spectrophotometer & Off-line & $(1,3,6,24)^{\mathrm{c}},(24)^{\mathrm{b}}$ \\
\hline & Dry weight (oven) & Off-line & $(3,6,8)^{\mathrm{c}},(8,15,24,25)^{\mathrm{b}}$ \\
\hline & Cell counting & Off-line & $(3,8,27)^{\mathrm{c}},(8,26,28)^{\mathrm{b}}$ \\
\hline & Optical density Sensor (NIR) & On-line & $(29)^{\mathrm{c}},(19)^{\mathrm{b}}$ \\
\hline & FIA + Spectrophotometer & On-line & $(11)^{\mathrm{b}},(11)^{\mathrm{fb}}$ \\
\hline & Software sensor & On-line & $(12)^{\mathrm{fb}},(28,30-34)^{\mathrm{b}}$ \\
\hline & Turbidity probe & On-line & $(35)^{\mathrm{c}},(33)^{\mathrm{b}}$ \\
\hline \multirow[t]{4}{*}{ Biomass properties } & Fluorometry & Off-line & $(6)^{\mathrm{c}},(15,19,20,26,36)^{\mathrm{b}}$ \\
\hline & In situ microscope (ISM) & On-line & $(37)^{\mathrm{b}}$ \\
\hline & Infrared spectroscopy & Off-line & $(38)^{\mathrm{b}}$ \\
\hline & Software sensor & On-line & $(33)^{\mathrm{b}}$ \\
\hline \multirow[t]{5}{*}{ Biomass composition (lipids, protein carbohydrates) } & Gas Chromatography & Off-line & $(4,24,39)^{\mathrm{c}},(24)^{\mathrm{b}}$ \\
\hline & Flow citometry & Off-line & $(40)^{c}$ \\
\hline & FTIR & Off-line & $(38)^{\mathrm{b}}$ \\
\hline & Fluorometry & Off-line & $(36)^{b}$ \\
\hline & Solvent precipitation & Off-line & $(41)^{\mathrm{c}},(41)^{\mathrm{b}}$ \\
\hline
\end{tabular}

Legend: NIR-near infrared; FIA-Flow injection analysis; FTIR-Fourier transform infrared; PAM-Pulse amplitude modulated.

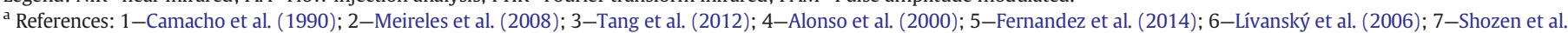

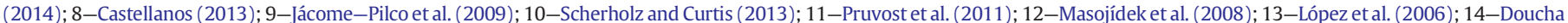

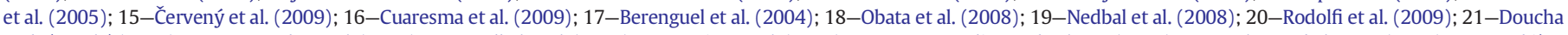

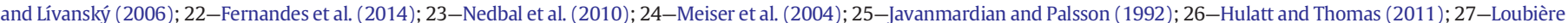

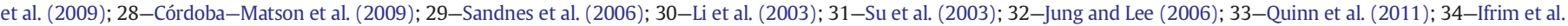

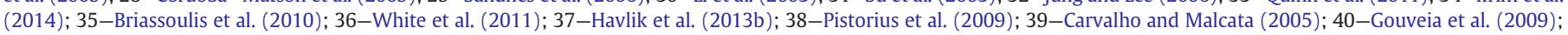
41-Moreno et al. (1998)-The superscript indicates the cultivation mode used during the study: Batch (b); Continuous (c); Fed-batch (fb). 


\subsubsection{Control}

Control of microalgae and cyanobacteria cultivation systems is usually done using feedback or feedforward control. Feedback control measures the process output and compares it with a reference value, changing the input variable in order to approximate the output to the reference (Fonseca and Teixeira, 2007). In feedforward control strategies, mathematical models act as observers (or estimator) that will evaluate the current state, predict the result and, if necessary, implement actions to maintain the culture in the predetermined state (Fonseca and Teixeira, 2007; Toroghi et al., 2013). It is very common to implement feedforward control as an add-on to feedback control. In these situations, the feedforward part controls the major disturbance, and the feedback part controls everything else that might cause the process variable to deviate from its set point. In control systems there are always a non-manipulated monitored variable (e.g., pH, biomass concentration properties) and an independent and manipulated variable (e.g., $\mathrm{CO}_{2}$ injection, dilution rate, light intensity), which is the control variable (Table 3). Usually the control of $\mathrm{pH}$ is a feedback control, i.e., when $\mathrm{pH}$ is increased above a reference value, $\mathrm{CO}_{2}$ (or acid) is added to the culture in order to decrease the $\mathrm{pH}$ value (Fernandez et al., 2014; Loubière et al., 2009). The $\mathrm{pH}$ control through the injection of $\mathrm{CO}_{2}$ is the most common method, mainly because it is also a source of inorganic carbon.

Generally, biomass feedback controls are applied on batch or semicontinuous cultivation systems (Meireles et al., 2008; Sandnes et al., 2006), while feedforward controls (that use biomass growing models) are proposed for continuous systems (Baquerisse et al., 1999; Becerra-Celis et al., 2008; Quinn et al., 2011). The main strategies for control of biomass concentration developed are feedback control based in spectrophotometer techniques (Meireles et al., 2008; Sandnes et al., 2006), feedforward control based in the inflow rate (Abdollahi and Dubljevic, 2012; Becerra-Celis et al., 2008) or a joint control (feedback and feedforward) using $\mathrm{CO}_{2}$ gas flow rate accordingly with the light intensity regime (Buehner et al., 2009).

\section{Table 3}

Common dependent parameters measured in the cultivation of photosynthetic microorganism and corresponding control strategies.

\begin{tabular}{|c|c|c|c|}
\hline $\begin{array}{l}\text { Dependent } \\
\text { parameter }\end{array}$ & Control variable & Control type & References $^{\mathrm{a}}$ \\
\hline \multirow[t]{4}{*}{$\mathrm{pH}$} & $\begin{array}{l}\mathrm{CO}_{2} \text { gas flow } \\
\text { rate }\end{array}$ & Feedback & $\begin{array}{l}(1-10)^{\mathrm{c}},(11)^{\mathrm{fb}}, \\
(8,9,12-15)^{\mathrm{b}},\end{array}$ \\
\hline & & Feedback\&Feedforward & $(6)^{\mathrm{c}},(16)^{\mathrm{b}}$ \\
\hline & $\begin{array}{l}\text { Acid/base } \\
\text { control }\end{array}$ & Feedback & $(17,18)^{c},(19)^{b}$ \\
\hline & $\begin{array}{l}\text { Balanced } \\
\text { medium }\end{array}$ & Feedback & $(20)^{\mathrm{b}}$ \\
\hline \multirow[t]{4}{*}{$\begin{array}{l}\text { Biomass } \\
\text { concentration }\end{array}$} & Dilution rate & Feedback & $\begin{array}{l}(1,3,21)^{\mathrm{c}},(22)^{\mathrm{fb}}, \\
(22)^{\mathrm{b}}\end{array}$ \\
\hline & & Feedback\&Feedforward & $(7)^{\mathrm{c}}$ \\
\hline & Light intensity & Feedback & $(21)^{\mathrm{c}},(23)^{\mathrm{b}}$ \\
\hline & $\begin{array}{l}\mathrm{CO}_{2} \text { \& Light } \\
\text { intensity }\end{array}$ & Feedback\&Feedforward & $(24)^{\mathrm{c}}$ \\
\hline \multirow{4}{*}{$\begin{array}{l}\text { Biomass } \\
\text { composition }\end{array}$} & Dilution rate & $*$ & $(8,24-27)^{\mathrm{c}},(8)^{\mathrm{b}}$ \\
\hline & Light intensity & $*$ & $(27)^{\mathrm{c}}$ \\
\hline & $\mathrm{CO}_{2}$ & $*$ & $(27)^{\mathrm{c}}$ \\
\hline & $\mathrm{N}$-limitation & $*$ & $(8,24)^{\mathrm{c}},(8)^{\mathrm{b}}$ \\
\hline
\end{tabular}

aReferences: 1-James and Al-Khars (1990); 2 .-Fernandez et al. (2014); 3-Loubière et al. (2009b); 4-Shozen et al. (2014); 5-Fuentes et al. (1999); 6-Berenguel et al. (2004); 7-Becerra-Celis et al. (2008); 8-Moreno et al. (1998); 9-Meiser et al. (2004); 10-Cuaresma et al. (2009); 11-Doucha and Lívanský (2006); 12-Červený et al. (2009); 13-Masojídek et al. (2008); 14-López et al. (2006); 15-Li et al. (2003); 16-Buehner et al. (2009); 17-Castellanos (2013); 18-Jácome-Pilco et al. (2009); 19-Nedbal et al. (2010); 20-Scherholz and Curtis (2013); 21-Sandnes et al. (2006); 22-Meireles et al. (2008); 23-Choi et al. (2003); 24-Gouveia et al. (2009), 25-Reis et al. (1996); 26-Alonso et al. (2000); 27-Carvalho and Malcata (2005)-The superscript indicates the cultivation mode used during the study: Batch (b); Continuous (c); Fed-batch (fb).

${ }^{*}$ The control variables are used to control the biomass composition but this is not made automatically.
Model-based bioprocesses control is not yet a mature technology being currently a fundamental research field with high potential. Despite recent progress, there are still technological, mathematical, engineering and biological issues to solve in the on-line monitoring and control of photosynthetic microorganisms cultivation. Solving these issues will be essential for developing cost-effective and reliable processes for the continuous cultivation of these microorganisms.

\subsection{Downstream processes}

The manufacturing of microalgal and cyanobacterial based products, as well as in other biotechnological processes, is divided into upstream and downstream processing. Whereas upstream processing comprises steps like the inoculum preparation, cultivation in the seed PBR and the full-scale cell cultivation, downstream processing includes all the process steps from cell harvest to the final product. Depending on the product of interest, after the biomass recovery, several processes such as biomass processing (e.g., drying), cell disruption, metabolite extraction from the biomass and purification of the extract product can be, or not, performed (Jungbauer, 2013; Mirón et al., 2003). Although with different operational dynamics, the flow diagrams for continuous and batch downstream processing are essentially the same.

The cost associated to the downstream processes varies with the type of technology used and the density of cell culture but, for example, the complete downstream process can be responsible for $60 \%$ of the total biodiesel production cost (Kim et al., 2013; Mata et al., 2010).

The utilization of continuous downstream processes is not mandatory, even when the cell cultivation is performed using a continuous mode. In fact, in industrial plants operating in continuous mode, the downstream processing is usually done in a given period of the day (when the operators are in the facility), and not in a truly continuous way. This necessity for permanent supervision associated to continuous downstream is the main disadvantage of this strategy of continuous processing since it increases the labor cost.

However, the utilization of downstream processes in continuous mode, allows higher productivity and flexibility due to the possibility to monitor and control the downstream steps in real time (Jungbauer, 2013). Additionally, it can be very useful in processes in which a toxic, inhibitory, volatile or extracellular compound is present (Niedermeyer et al., 2014). Continuous downstream processes could also reduce or supress the need for a storage step, reducing costs and the risk of product deterioration or loss of valuable properties that could occur during storage (Jungbauer). However the suppression/presence of a storage step is highly dependent on the selected downstream processes because, in order to eliminate this step the flowrate of downstream units, must fit the flowrate of upstream step (cultivation) which is usually very low. Also, the capital costs can be considerably decreased using continuous downstream processing (Jungbauer, 2013).

\subsubsection{Harvesting}

Harvesting has a very significant influence in the economic aspects of microalgal and cyanobacterial biomass production, being responsible for $20-30 \%$ of the total biomass production cost (Gudin and Thepenier 1986; Kim et al., 2013).

Microalgal and cyanobacterial cells recovery can be a challenging task due its small size (3-30 $\mu$ m diameter), typical low cell densities $\left(<0.5 \mathrm{~kg} \mathrm{~m}^{-3}\right)$ and large volumes (Molina Grima et al., 2003) Usually, their harvesting requires one or two solid-liquid separation processes, being the most common methods the centrifugation, filtration and sedimentation that can be preceded by a flocculation step (Molina Grima et al., 2003). Microalgal and cyanobacterial cell recovery methods have been extensively reviewed elsewhere (Chen et al., 2011; Christenson and Sims, 2011; Grima et al., 2004; Kim et al., 2013; Molina Grima et al., 2003; Shelef et al., 1984).

Regarding, specifically, to continuous photosynthetic cell separation, filtration and centrifugation stands out as the most widely used 
techniques (Rossignol et al., 1999). Comparing the costs of these two technologies, it is possible to conclude that filtration units are more suitable for small-scale systems $\left(<2 \mathrm{~m}^{3} \mathrm{~d}^{-1}\right)$, while continuous centrifugation is a more economically attractive technology for large scale systems $\left(>20 \mathrm{~m}^{3} \mathrm{~d}^{-1}\right.$ ) (Rossignol et al., 1999). If high-quality cells are required for human consumption (e.g., Chlorella vulgaris, Spirulina) continuous harvesting by solid ejecting or nozzle-type disk centrifuges is highly recommended, since they can be easily cleaned and sterilized (Grima et al., 2004; Shelef et al., 1984).

In addition to the previously mentioned advantages, the utilization of continuous harvesting techniques also allows an extended use of the equipment. Sim et al. (1988) noticed that the utilization of the filtration system in continuous mode allowed an economic life exceeding 500 operation hours of the filter cloth. They concluded that the excessive use of chemicals used for belt washes (in each batch operation) reduced the belt life. Examples of harvesting techniques (mainly filtration, centrifugation and flocculation) used to continuously remove microalgal and cyanobacterial cells have been described elsewhere (Christenson and Sims, 2011; Grima et al., 2004; Heasman et al., 2000; Lee et al., 2010; Molina Grima et al., 2003; Rossignol et al., 1999)

Alternative methods have also been tested for the continuous harvesting of microalgal and cyanobacterial cells. Kim et al. (2012, 2014) harvested the microalgae Nannochloris oculata and Nannochloropsis oceanica, respectively, using the electrolytic method, without subjecting the cells to any kind of shear stress. Additionally, an ultrasonic continuous harvesting process has been successfully tested by (Bosma et al., 2003), in order to recover Monodus subterraneus cells. Continuous harvesting is, clearly, more efficient than processing a single large volume, which is typical of batch cultivations (Ganuza and Izquierdo, 2007). Coupled with a continuous cultivation system, the cost of a continuous harvesting process can be even lower due the typicall higher operating cell densities (Borowitzka, 1999).

\subsubsection{Biomass processing and metabolite recovery}

The product of interest will determine which steps are required and which is the most suitable technique for each process.

3.4.2.1. Drying. The need for a dehydration or drying step can be due to different factors such as: the necessity of a more concentrated cell paste (harvested biomass slurry present $5-15 \%$ dry solids); the biomass is the final product and therefore there is the need to extend the shelflife; and some extraction and disruption methods are more effective in dry biomass (Belarbi et al., 2000; Grima et al., 2004; Molina Grima et al., 2003; Shelef et al., 1984). Sun drying, spray drying, drum drying and freeze-drying are the most widely used methods for dry microalgae and cyanobacteria biomass, however the selection of the most suitable method will greatly depend on the final product value and required quality (Molina Grima et al., 2003). All these techniques are suitable for continuous operation and their performance could be increased due to the reduction of biomass to be processed per unit of time. The utilization of continuous mode will reduce the required drying facilities/ equipment scale, thus reducing the investment and operational cost.

3.4.2.2. Cell disruption. The utilization of cell disruption methods is usually necessary to recover intracellular products. The most commonly used methods to disrupt microalgal and cyanobacterial cells are autoclave, ultrasound, homogenization, and bead milling. Chemical and biological methods like organic solvents, acids, alkalis and enzymes can be also used (Mendes-Pinto et al., 2001; Molina Grima et al., 2003; Safi et al., 2014). As in the harvesting step, the utilization of cell disruption techniques in continuous mode increase the process flexibility, reduce the required equipment scale and reduce (or even suppress) the need for a storage step.

3.4.2.3. Metabolite extraction. Recently, in order to incorporate the extraction step in continuous production systems, several extraction techniques (mainly lipid extraction) have been tested using this mode of operation. Balasubramanian et al. (2011) tested hexane assisted by a microwave system for a continuous lipid extraction from Scenedesmus obliquus cells in order to reduce solvent utilization (due to an efficient heating) and result in a more economical process. Iqbal and Theegala (2013) developed a continuous flow lipid extraction system (from Nannochloropsis sp.), which, using conventional solvents, was able to keep Soxhlet efficiencies while reducing the energy consumption, the solvent utilization and the extraction time. The utilization of pulsed electric fields is a very promising technique for continuous extraction of products (mainly proteins) from microalgal and cyanobacterial cells. The main effects of this technique are the cell disruption or the electroporation phenomena, which promotes the metabolite extraction. Nevertheless, the utilization of pulsed electric fields in this photosynthetic microorganisms is not fully established (Coustets et al., 2013; Goettel et al., 2013) and thus more research studies need to be performed and should include scale-up and economic evaluation.

3.4.2.4. Metabolite purification. The utilization of continuous purification processes only causes an increase in the purification efficiency step in situations where the product is highly unstable. In this particular situation, an immediate purification is required in order to produce a high product:impurity ratio. In all the other situations, it is preferable to perform the purification step in batch mode (Jungbauer, 2013).

\subsection{Feasibility and economics}

The evaluation of continuous photoautotrophic cultures economics' depend on several factors, such as: $i$ ) localization, which will influence the land, building and labor costs as well as the system productivity (in the case of outdoor cultures); ii) the type of PBR used, which is going to determine the investment and the maintenance costs; and iii) the downstream process techniques; and $i v$ ) final product and its commercial value.

Besides the lack of rigorous economic studies for large scale microalgae and cyanobacteria biomass production (Acién et al., 2012; Molina Grima et al., 2003), it is significant to note that several of the technical and economic evaluations, even if based on estimations, are performed for continuous (Acién et al., 2012; Cheng-Wu et al., 2001; Harun et al., 2011; Jaramillo et al., 2012; Marzocchella et al., 2010; Molina Grima et al., 2003; Powell and Hill, 2009) or semi-continuous (J. Li et al., 2011; Y. Li et al., 2011) cultivation systems.

The available techno-economic evaluations are very diverse (Table 4) due to distinctive economic approaches, final product, annual production, PBR and downstream methods. These distinctive approaches and the different final products do not allow very accurate comparisons between the different studies but give us the idea of the relative weight of each parameter in the economic performance and the changes that need to be implemented in order to make the process more cost-effective.

Considering only the evaluations of pilot or large scale cultivations units it is possible to observe from Table 4 that, depending on the final product, there is a considerable discrepancy in the proposed annual production. For example, the annual production of astaxanthin and eicosapentaenoic acid (EPA) is set to a production volume that is, approximately, 200-35,000 smaller than the proposed scenarios for biomass and biodiesel production, respectively.

As the two scenarios presented by Acién et al. (2012) demonstrate, the annual production volume has a huge influence on product cost and the relative weight of each item in the process economic performance. These authors performed a cost analysis using the microalgae productivity, nutrients and power consumption data obtained from a real continuous cultivation (2 years) of the microalga Scenedesmus almeriensis in a $30 \mathrm{~m}^{3}\left(10 \times 3 \mathrm{~m}^{3}\right)$ closed tubular PBR.

For the continuous biomass production become economically feasible, the costs of the PBR (which represent $47 \%$ of major equipment costs 
Table 4

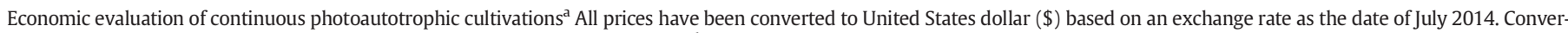
sions of Euros $(€)$ into $\$$ have been made based on an exchange rate of $0.75 \$ / € ;{ }^{\text {b }}$ open pond; ${ }^{\mathrm{c}}$ closed tubular PBR.

\begin{tabular}{|c|c|c|c|c|c|}
\hline Microorganism & Product & Annual Production & Product cost ${ }^{a}$ & Biomass cost ${ }^{a}$ & Reference \\
\hline Scenedesmus almeriensis & Biomass & $\begin{array}{l}3.8 \mathrm{t} \\
200 \mathrm{t}\end{array}$ & $\begin{array}{l}\$ 51.7 \mathrm{~kg}^{-1} \\
\$ 9.45 \mathrm{~kg}^{-1}\end{array}$ & $\begin{array}{l}\$ 51.7 \mathrm{~kg}^{-1} \\
\$ 9.5 \mathrm{~kg}^{-1}\end{array}$ & Acién et al. (2012) \\
\hline Phaeodactylum tricornutum & EPA & $0.43 \mathrm{t}$ & $\$ 4602 \mathrm{~kg}^{-1}$ & $\$ 32.2 \mathrm{~kg}^{-1}$ & Molina Grima et al. (2003) \\
\hline Haematococcus pluvialis & Astaxanthin & $0.90 \mathrm{t}$ & $\$ 718 \mathrm{~kg}^{-1}$ & $\$ 18 \mathrm{~kg}^{-1}$ & J. Li et al. (2011), Y. Li et al. (2011) \\
\hline $\mathrm{N} / \mathrm{D}$ & Biodiesel & $\begin{array}{l}35,300 \mathrm{~m}^{3 \mathrm{~b}} \\
35,300 \mathrm{~m}^{3 \mathrm{c}}\end{array}$ & $\begin{array}{l}\$ 2.6 \mathrm{~L}^{-1} \\
\$ 5.4 \mathrm{~L}^{-1}\end{array}$ & $\begin{array}{l}\mathrm{N} / \mathrm{D} \\
\mathrm{N} / \mathrm{D}\end{array}$ & Davis et al. (2011a) \\
\hline
\end{tabular}

(MEC)), downstream (45\% of MEC) and labor (52\% operational costs) should be reduced (Acién et al., 2012). To do so, these authors proposed and analyzed a scale-up to a production capacity of $200 \mathrm{t} / \mathrm{year}$ with some technological simplifications. This scale-up allowed an $82 \%$ reduction in the product cost, from 51.7 to $\$ 9.45 \mathrm{~kg}^{-1}$ (Table 4 ). . Other consequences of this scale-up were the reduction of relative weight of labor ( 52 to $7 \%$ of operational costs) and downstream process costs ( 45 to $2.2 \%$ of MEC) and an increase in PBR ( 47 to $94 \%$ of MEC) (Fig. 2) and depreciation costs (43 to $78 \%$ of operational costs).

From Fig. 2 it is possible to observe that the cost of closed PBRs is indeed one of the major costs in large scale continuous production, which is in accordance with other economic analysis (Harun et al., 2011). This is probably because the benefit of closed PBRs in large scale systems is not yet fully exploited (Davis et al., 2011; Posten, 2009) and also due to the elevated operational costs as the energy consumption, that can be 15 times higher than in open-air systems (Harun et al., 2011). Only in the study presented by Molina Grima et al. (2003) this was not observed, maybe because of the small volume of the PBRs $\left(0.8 \mathrm{~m}^{3}\right)$ when compared with the volume of the PBRs proposed by the other authors.

In order to verify the influence of the used cultivation system in the microalgal biodiesel economical feasibility, Davis et al. (2011) presented a simulation and comparison of a closed tubular PBR and an open pond, with the same annual production. These authors concluded that the biodiesel total production cost was $\$ 2.6 \mathrm{~L}^{-1}$ in the open pond and $\$ 5.4 \mathrm{~L}^{-1}$ in the closed tubular PBR scenario, attesting that the utilization of closed PBRs introduces significant additional costs.

A strategy to increase the economical feasibility of microalgal and cyanobacterial production, has been presented by Harun et al. (2011). These authors proved that an integrated biodiesel and biogas production facility would be technical and economical feasible because the integration of methane production systems (from microalgae biomass) will reduce the electricity need for operating the PBR, reducing the biodiesel production cost in 33\%. This integration was also proposed by other authors, however, from an energy balance perspective only when raceway pounds are applied the full system seems viable (Davis et al., 2011; Harun et al., 2011).

Another option to reduce costs during the continuous cultivation was suggested by Molina Grima et al. (2003). These authors claimed that enhancing $30 \%$ the biomass productivity, during the continuous cultivation of the microalga P. tricornutum for EPA production, through the improvement of the PBR design could decrease the biomass production cost in $20 \%$. Biomass production contributes, according to Molina Grima et al. (2003), to $40 \%$ of the cost of EPA.

It is known that downstream processes can have a very significant impact in annual costs and that is clear in the case of EPA production as suggested by Molina Grima et al. (2003). They verified that the recuperation of EPA is responsible for $60 \%$ of the annual production costs. In this case the impact of raw materials (organic solvents) costs for producing the crude oil and on the EPA purification by chromatography is very high. For the total biomass production costs the main factors were the operational (48\%) and fixed capital costs (39\%) in line with other works (Acién et al., 2012; J. Li et al., 2011; Y. Li et al., 2011).

An interesting approach was performed by J. Li et al. (2011), Y. Li et al. (2011) that, for the production of astaxanthin from Haematococcus, obtained a production cost $\left(\$ 718 \mathrm{~kg}^{-1}\right)$ lower than the estimated $\left(\$ 3000 \mathrm{~kg}^{-1}\right.$ ) for established facilities. Moreover, this value is also lower than the price for synthethic astaxanthin, which is around $\$ 1000 \mathrm{~kg}^{-1}$. The high costs of PBRs presented by J. Li et al. (2011), Y. Li et al. (2011) (Fig. 2) are due to their hybrid system (Brennan and Owende, 2010) that is composed by two closed PBRs that provide viable cell for a raceway pound where microalgae are subject to severe stress conditions (two step operation). The main aim of this hybrid system is to optimize the astaxanthin production (Acién et al., 2012; J. Li et al., 2011; Y. Li et al., 2011), however it is still operating at pilot scale and not in fully continuous, but in a semi-continuous mode. In addition, this system has been used in China where land and labor costs (20\% of annual costs) are significantly lower than in other regions of the world. These authors state that if the same production unit was installed in USA the labor would increase from $\$ 120$ to $\$ 600$ per $\mathrm{kg}$ of astaxanthin. In this production unit presented by J. Li et al. (2011), Y. Li et al. (2011), the downstream processes (14\% of MEC) are composed by a two-step harvesting method (sedimentation tank and centrifugation) followed by a spray drying step. For an increased reduction in downstream process costs, they suggest a pre-sedimentation of microalgal cells in the raceway pond by stopping the paddle wheel. This processing strategy avoids the use of flocculating agents and will allow the production of inexpensive astaxanthin with the current technology (Acién et al., 2012; J. Li et al., 2011; Y. Li et al., 2011).

The analysis of the report published by Pienkos (2008) (supported by Sandia National Laboratories and National Renewable Energy
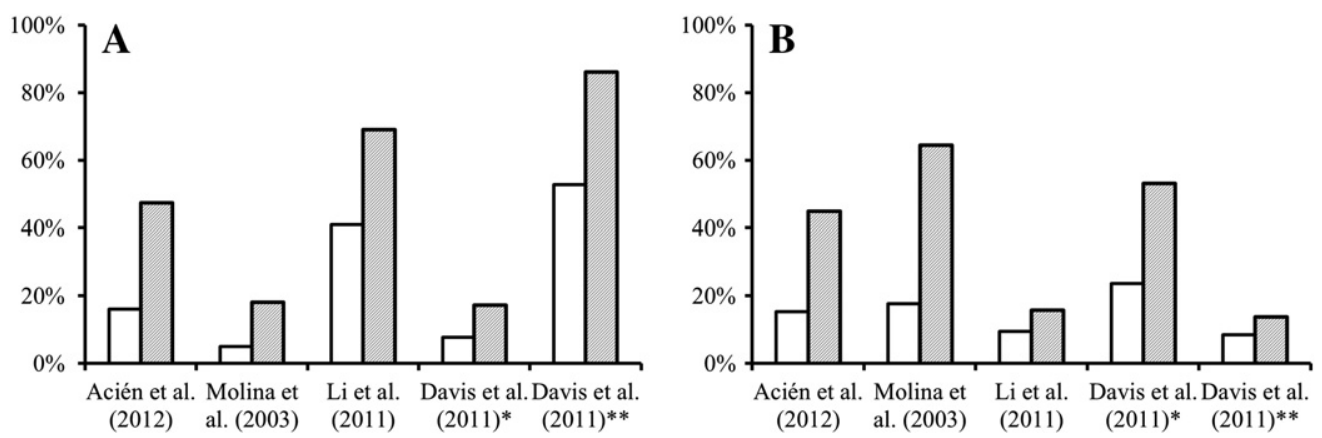

Fig. 2. Impact of PBRs (A) and downstream equipment costs (B) on total fixed (open column) and major equipment cost (filled column). 
Laboratory) demonstrates the disparities that different approaches introduce in the production cost. This report compares the cost analysis of oil production from photosynthetic microalgae only (considering both batch and continuous processes), based on twelve different references. Despite the fact that this report compares different approaches to produce the same product, the range of cost presented in this report is very wide ( $\$ 0.24 \mathrm{~L}^{-1}$ to $\$ 11.2 \mathrm{~L}^{-1}$ ) with an average cost of $\$ 5.1 \mathrm{~L}^{-1}$ and a standard deviation of $\$ 7.6 \mathrm{~L}^{-1}$ (Sun et al., 2011).

These economic analyses, even if based in estimations, can be used to detect the major factors influencing the production costs and can represent a valuable tool to identify the technical problems that need to be solved in order to achieve economic viability of microalgal and cyanobacteria cultivation systems in general and in continuous systems in particular.

Despite the different economic approaches, all these studies emphasize the need to decrease the production cost in order to make continuous cultivation of photosynthetic microorganisms a feasible industrial process.

\section{Applications}

After a description of the continuous cultivation principles, the advantages and challenges of its application to the cultivation of photosynthetic microorganisms and the description of the equipment and techniques involved, it is imperative to scrutinize the applications of this mode of operation in the microalgae and cyanobacteria study and cultivation. In this review the application of continuous cultivation will be divided according to the intended purpose: $i$ ) as a research tool and ii) as a production strategy.

\subsection{Research tool}

Among all the characteristics inherent to continuous cultivations, the ones that justify its use as a research tool in physiological, ecological genetic and biochemical studies (Hoskisson and Hobbs, 2005) are: i) possibility to pre-set and control specific growth rate; ii) select and control the metabolic state; iii) significant amount of cells with defined properties possible to be obtained using a lab-scale PBR; iv) single independent variables (e.g., $\mathrm{pH}$, temperature, specific growth rate) can be manipulated one at a time; $v$ ) possibility to choose one, or combinations of, limiting nutrient(s) and; and vi) defined, constant and controllable physico-chemical conditions (Cooney, 1979; Dang et al., 2012; Fiechter, 1975; Hoskisson and Hobbs, 2005).

In an extensive overview about the continuous cultivation and its application as a research tool, (Hoskisson and Hobbs, 2005) refers that, after a decline, continuous cultivation recently re-emerged as a preferential option in studies of growth, nutrient limitation and stress responses. Several works on the effect of nutrient concentration (macronutrients such as nitrogen and phosphorus and trace metals, particularly iron) in the physiology, metabolism and biochemical composition of photototrophic microorganisms have been carried out in the last years using continuous cultivation as a tool (Bougaran et al., 2010; Collins et al., 2001; Dang et al., 2012; Gauthier and Turpin, 1997; Gress et al., 2004; Hagstrom et al., 2010; Klok et al., 2013a, 2013b; Lyck et al., 1996; Middlemiss et al., 2001; Sonier and Weger, 2010; Su et al., 2012; Utkilen and Gjølme, 1995; Weger and Espie, 2000; Weger et al., 2002, 2006, 2009; Wirtz et al., 2010).

Besides nutrient concentration, also the influence of salt adaptation, light quality and quantity, initial biomass concentration, turbidity, temperature, culture age, and dilution rate have been studied using continuous cultivation mode (Alonso et al., 2000; Blumwald and Tel-or, 1984; Camacho et al., 1990; Carvalho and Malcata, 2005; Imaizumi et al., 2014; Lamers et al., 2010; Madhyastha and Vatsala, 2007; Maeda et al., 2006; San Pedro et al., 2013; Sassano et al., 2007; Sassano et al., 2010; Sobczuk and Chisti, 2010; Utkilen and Gjølme, 1992). Blumwald and Tel-or (1984) tested the influence of the salt-adaptation phenomenon in the physiological state of the cyanobacterium Synechococcus 6311. Utkilen and Gjølme (1992) studied in a continuous PBR, the effects of light intensity and light quality on toxin production by Microcystis aeruginosa, while Lamers et al. (2010) using a turbidostat, tested the effect of the same parameter on carotenoid and fatty acid metabolism of the alga Dunaliella salina. The influence of dilution rate in the kinetics of Spirulina platensis during continuous cultivation have been investigated by Sassano et al. (2007), whereas Sobczuk and Chisti (2010) tested the effect of dilution rate and temperature in lipid content and fatty acid profiles of the microalga Choricystis minor. A turbidostat and a chemostat were used by Maeda et al. (2006) to evaluate the effect of turbidity on starch production by Chlamydomonas sp.

Continuous cultivation at laboratory scale can also be used as a tool for the development and characterization of new photoautotrophic processes, since it allows the optimization of individual process factors by keeping all the other significant parameters constant (Czitrom, 1999; Guedes et al., 2014). For example, S. platensis grown continuously in a PBR was used during the design and evaluation of a process for recovery and treatment of this cyanobacterium, to be used as food (Morist et al., 2001).

\subsection{Production strategy}

To increase the feasibility of industrial processes based on the cultivation of microalgal or cyanobacterial cells: $i$ ) the investment and operational costs should be reduced (e.g., reducing land requirements, increasing process automation, decreasing downstream costs); ii) the potential of microalgae and cyanobacteria should be maximized (e.g., optimizing productivities and/or adopting biorefinery concept); and iii) the process and/or the product should be controllable and reliable (Harrison et al., 2013; Klok et al., 2013b; Wijffels et al., 2010). As previously mentioned (Section 2.1 Advantages) the utilization of continuous cultivation allows meeting some of these needs, however the selection of this mode of operation is most of the times due to the control and consistency of the process and product that this approach allows. The application of continuous production of photosynthetic microorganisms as a production strategy can be divided in three categories: $i$ ) removal of nutrients, organic contaminants and heavy metals from wastewaters; ii) to be used as feed in aquaculture and; and iii) to be used as raw material to chemicals and biofuels.

\subsubsection{Wastewater treatment}

The most common and widely studied application of microalgal and cyanobacterial continuous cultivations is the removal of nutrients, organic contaminants and heavy metals from wastewaters (Table 5) where, the utilization of these microorganisms could provide some additional advantages like the production of high-value chemicals (metabolites) and the production of photosynthetic oxygen required by bacteria to biodegrade hazardous pollutants (Muñoz and Guieysse, 2006).

Depending on the wastewater composition and in the sensitivity of the microorganisms, two different approaches can be adopted: $i$ ) well mixed PBR with free cells and biomass recirculation in order to avoid the toxic effect (Muñoz and Guieysse, 2006); and ii) immobilized cells that allow a high degrees of purification and a simple process operation (Aksu, 1998). Continuous cultivation is especially suitable for removal of pollutants because it allows an efficient utilization and management of mixed substrates and mixed cultures (Cooney, 1979) and the removal of the limiting nutrients (in this case the pollutant) from the culture medium (McGinn et al., 2012). Additionally, the use of continuous cultivation process allows working with toxic substrates, since this mode of operation reduce the inhibitory effect of toxic compounds because cells experienced a lower toxic concentration per cell (due to higher cell concentration) and a lower contact time between the cells and the toxic compounds. For these reasons, McGinn et al. (2012) considered continuous cultivation as the only feasible approach for wastewater 
Table 5

Continuous systems used for wastewater treatment.

\begin{tabular}{|c|c|c|c|}
\hline Microorganisms & Growth medium & Experimental system & Reference \\
\hline Chlorella sp. $^{(\mathrm{F})}$ & Municipal wastewater & Coil reactor & Y. Li et al. (2011) \\
\hline Scenedesmus obliquus ${ }^{(\mathrm{F})}$ & Urban wastewater & Flat panel PBR & Ruiz et al. (2013) \\
\hline Chlorella vulgaris/bacterial consortium $^{(\mathrm{I})}$ & Synthetic wastewater & Stirred tank & De-Bashan et al. (2002) \\
\hline Chlorella sorokiniana $^{(\mathrm{F})}$ & Synthetic urine & Flat panel & Tuantet et al. (2014) \\
\hline Spirulina platensis ${ }^{(\mathrm{F})}$ & Synthetic urine & Column & Yang et al. (2008) \\
\hline Oocystis sp./Scenedesmus sp./bacterial consortium ${ }^{(\mathrm{F})}$ & Digested swine slurry & Open pond and tubular PBR & Molinuevo-Salces et al. (2010) \\
\hline Scenedesmus incrassatulus ${ }^{(\mathrm{F})}$ & Chromium (VI) & Split cylinder airlift & Jácome-Pilco et al. (2009) \\
\hline Microcystis sp. ${ }^{(\mathrm{I})}$ & Copper solution & Column & Pradhan and Rai (2000) \\
\hline Chlorella ellipsoidea ${ }^{(\mathrm{F})}$ & Chromium and cadmium (II) & Erlenmeyer flask & Aoyama and Okamura (1993) \\
\hline Microcystis spp. ${ }^{(\mathrm{F})}$ & Chromium (VI), cadmium (II) and copper (II) & Erlenmeyer flask & Rai and Tripathi (2007) \\
\hline Scenedesmus incrassatulus ${ }^{(\mathrm{F})}$ & Chromium (VI), cadmium (II) and copper (II) & Erlenmeyer flask & Peña-Castro et al. (2004) \\
\hline Phormidium bigranulatum ${ }^{(\mathrm{F})}$ & Lead (II), copper (II), cadmium (II) & Flat chambers & Kumar et al. (2012) \\
\hline Chlorella sorokiniana $^{(\mathrm{F})}$ & Sodium salicylate & Stirred tank & Muñoz et al. (2004) \\
\hline
\end{tabular}

(F) free cells; ${ }^{(I)}$ immobilized cells.

treatment based in photosynthetic microorganisms. For the removal of toxic pollutants, Chlorella and Scenedesmus sp. are typically selected due to its fast growth and high resistance, which make them naturally dominate most continuous microalgal based treatment systems (Muñoz and Guieysse, 2006).

\subsubsection{Feed for aquaculture}

Cultivation of microalgae to be used as feed for larvae and juveniles of bivalve molluscs is usually performed in batch mode (Bougaran et al., 2003) and is considered the major bottleneck in nursery culturing of molluscs (Fabregas et al., 1986) since it represents up to $30 \%$ of the total cost of production (Valenzuela-Espinoza et al., 1999). Additionally, in batch systems, the cell composition it is not constant over time.

For example, Bougaran et al. (2003) refer that during the cultivation of I. galbana affinis, the cells shows higher protein content during exponential phase and higher carbohydrate and lipid content during stationary phase. Also Marchetti et al. (2012) used the continuous cultivation of the same microalga to determine the optimal conditions (irradiance, temperature, $\mathrm{pH}$ and concentrations of nitrogen and phosphorus) in order to maximize the productivity of this microalga, frequently used as food for various bivalve larvae. Loubière et al. (2009) refer that the continuous cultivation of I. affinis galbana, intended to be used as feeding in a mollusk hatchery, led to a biomass production with stable quality and quantity. Using a considerable large $(200 \mathrm{~L})$ vertical airlift PBR, James and Al-Khars (1990) tested at pilot scale the continuous cultivation of marine microalgae Nannochloropsis Strain MFD-2 and Chlorella Strain MFD-1. These authors described this PBR and this mode of operation, as very suitable for the production of these microalgae for aquacultural purposes, since the biomass productivity (50.6 and $169.7 \mathrm{~g} \mathrm{~m}^{-3} \mathrm{~d}^{-1}$ ) for Nannochloropsis Strain MFD-2 and Chlorella Strain MFD-1, respectively, was considerably higher than with the conventional methods. Additionally, in fish production pond, the dissolved oxygen concentration usually limits the system productivity. Therefore, Drapcho and Brune (2000) tested the partitioned aquaculture system, in which the fish productivity is maximized by increasing the oxygen production through the continuous photoautotrophic cultivation of microalgae. In this system the continuous microalgae cultivation is integrated in the fish production system.

Consequently, continuous cultivation of photosynthetic microorganisms to be used in aquaculture can be considered as a very attractive option.

\subsubsection{Chemicals and biofuels}

The utilization of microalgal or cyanobacterial cells as raw material for chemicals and biofuels is probably the most promising application of these cells.

Continuous phototrophic cultures have been tested as a very attractive strategy for the production of high-value products such as astaxanthin. Del Río et al. (2005) demonstrated the feasibility of continuous astaxanthin production through the continuous cultivation of the microalga $H$. pluvialis in a bubble column PBR, achieving one of the highest astaxanthin productivities $\left(5.6 \mathrm{mg} \mathrm{L}^{-1} \mathrm{~d}^{-1}\right)$ found in the literature. Also, the feasibility of the continuous cultivation of $H$. pluvialis for astaxanthin in a $25 \mathrm{~m}^{3}$ closed tubular PBR operating in continuous mode has been proved in the Aquasearch facility (Guedes et al., 2011; Olaizola, 2000). The continuous production of other high-value products like antibiotics from the cyanobacterium Scytonema sp. (Chetsumon et al., 1995), docosahexaenoic acid using the microalga Schizochytrium (Ganuza and Izquierdo, 2007); $\beta$-carotene from D. salina (Kleinegris et al., 2011) and lutein from the microalga Muriellopsis sp. have been also successfully performed. Continuous cultures have been widely tested as a strategy to maximize lipid and starch accumulation for further biodiesel and bioethanol production. This option by continuous mode is due to the fact that, in opposition to what happens in batch cultivations, in continuous cultivations simultaneous microbial growth and accumulation of these storage compounds can be achieved through the selection of a suitable dilution rate (Falkowski and Raven, 2007; Lyck et al., 1996; Mairet et al., 2011). Recently Wen et al. (2014) tested the effect of nitrate concentration in lipid productivity of the microalga Chlorella pyrenoidosa, while Sobczuk and Chisti (2010) evaluated the effect of temperature and dilution rate in the lipid productivity of the microalga C. minor. Also, Wang et al. (2013), studied, during the mixotrophic continuous cultivation of the microalga Chlorella protothecoides, the relationship between nitrogen availability and lipid accumulation. Also the production of molecular hydrogen through the continuous cultivation of the cyanobacterium Anabaena variabilis has been successfully tested (Markov, 1993).

\subsection{Performance of phototrophic cultivations-batch vs continuous}

In order to determine the most suitable cultivation mode, different authors have performed and compared batch and continuous cultivations. It is known that microorganisms usually show higher productivity in continuous cultivations when compared to batch (Castellanos, 2013), however this superiority must be achieved through the utilization of near optimal cultivation parameters, namely $D$. Thus, depending on the microorganism, operational conditions and product of interest, different scenarios can be found in the literature (Table 6).

The comparison of continuous and batch cultivations lead to the conclusion that, depending on the circumstances, the benefit of continuous systems can be variable. For example, Cohen et al. (1991) tested an open-air (open-pond) and a closed PBR (polyethylene sleeves hung on a frame) in batch and continuous mode for the cultivation of the microalga Porphyridium sp. and, in both cultivation systems, biomass production was higher in the continuous mode. In an open-air PBR it was obtained a biomass production of $3.9 \mathrm{~g} \mathrm{~d}^{-1}$ in batch and $7.6 \mathrm{~g} \mathrm{~d}^{-1}$ in continuous mode, while the closed PBR allowed a biomass production of $10.2 \mathrm{~g} \mathrm{~d}^{-1}$ in batch and $17.7 \mathrm{~g} \mathrm{~d}^{-1}$ in continuous 
Table 6

Comparison of the performance obtained during batch and continuous cultivations of photosynthetic microorganisms.

\begin{tabular}{|c|c|c|c|c|c|}
\hline \multirow[t]{2}{*}{ Microorganism } & \multicolumn{2}{|c|}{ Productivity $\left(\mathrm{g} \mathrm{L}^{-1} \mathrm{~d}^{-1}\right)$} & \multicolumn{2}{|c|}{ Concentration $\left(\mathrm{g} \mathrm{L}^{-1}\right)$} & \multirow[t]{2}{*}{ Reference } \\
\hline & Batch & Continuous & Batch & Continuous & \\
\hline Scenedesmus sp. & 0.130 & 0.250 & - & - & McGinn et al. (2012) \\
\hline Chlorella minutissima & 0.143 & $0.039-0.137$ & - & - & Tang et al. (2012) \\
\hline Dunaliella tertiolecta & 0.049 & $0.046-0.091$ & - & - & Tang et al. (2012) \\
\hline Pavlova lutheri & 0.030 & 0.114 & 0.54 & 0.39 & Carvalho and Malcata (2005) \\
\hline Nannochloropsis sp. & - & - & $0.8-2.3$ & 2.9 & Zou et al. (2000) \\
\hline \multirow[t]{2}{*}{ Chlorella pyrenoidosa } & 0.216 & $0.417-0.641$ & 2.2 & 0.55 & Wen et al. (2014) \\
\hline & $0.096^{\mathrm{a}}$ & $0.124-0.144^{\mathrm{a}}$ & & & \\
\hline \multirow[t]{2}{*}{ Schizochytrium sp. } & $6.48-7.92$ & 7.68 & $15-15.7$ & 8.0 & Ganuza and Izquierdo (2007) \\
\hline & $1.1-1.2^{\mathrm{b}}$ & $0.96^{\mathrm{b}}$ & & & \\
\hline Spirulina platensis & 0.33 & 0.31 & & & Vernerey et al. (2001) \\
\hline Spirulina maxima & - & - & 1.60 & 2.99 & Samson and Leduy (1985) \\
\hline
\end{tabular}

cultivation. Chetsumon et al. (1995) compared the batch and continuous production of an extracellular antibiotic secreted by the cyanobacterium Scytonema sp. The results obtained by these authors, showed a three times higher antibiotic productivity in the continuous cultivation, when compared to the batch cultivation.

Other authors such as Zhu and Jiang (2008) and Kumar et al. (2012) did not notice significant differences between these modes of operation regarding the system productivity. Zhu and Jiang (2008) tested the production of $\beta$-carotene using continuous cultivation of the microalga $D$. salina in a helix tube PBR and the biomass and $\beta$-carotene production was equivalent to that described for batch cultures. While Kumar et al. (2012) used, in continuous and batch mode, the cyanobacterium Phormidium bigranulatum to successfully remove lead (II), copper (II) and cadmium (II) from aqueous solution. Despite high metal removal efficiency, the results closely matched the batch system. This similarity, combined with a very low $D$ required, lead the authors to the conclusion that, in this particular situation, the continuous system may not be practicable and it would be preferable to use a batch system. Using a continuous cultivation system, the cyanobacterium Microcystis was cultivated by Rai and Tripathi (2007) in the presence of chromium (VI), cadmium (II) and copper (II), as single metal species and as mixtures of two or three metals. The results demonstrated that Microcystis was able to remove $24-76 \%$ of the metals but, when compared with the efficiencies reported for batch cultures, only chromium (VI) was more efficiently removed in the continuous system (uptake of chromate is favored by actively growing cells). All these studies corroborate the idea that the relative performance of batch and continuous cultivation is highly dependent on the microorganism and its application. Therefore, before opting for continuous or batch cultivation, a rigorous study should be developed in order to determine the best operation mode and establish the optimal operating conditions.

Although the continuous cultivation does not always provide significant advantages in terms of productivity and efficiency, other characteristics that are intrinsic to this mode of operation (e.g., constant product quality) continue to favor continuous systems over batch systems.

\section{Conclusions and future perspectives}

The information presented in this review points out continuous cultivation as the most feasible approach for industrial microalgal and cyanobacterial biomass production. This mode of operation is the only option that guarantees a good control over the chemical environment ensuring a tailor-made biomass composition with constant product quality and production rate, reduced investment and operational costs, reduced time for cleaning and filling, smaller area requirements, higher productivities and operating cell densities, which means reduced harvesting costs. Despite all these advantages and although the continuous cultivation of photosynthetic microorganisms is fully established as a valuable research tool, its wider application in mass photoautotrophic cultivation is not a reality yet. This fact is due to some technical difficulties addressed to continuous systems but also due to some distrust relatively to continuous processes (result of the lack of rigorous technical-economic assessments) and some resistance to abandon the, already established, batch systems. To overcome this, it is necessary to provide illustrative case studies where the advantages of continuous systems are clearly demonstrated and combined with a rigorous and realistic technical-economic assessment. Also, the emergence of successful microalgae or cyanobacteria continuous cultivation projects (with reliable productivity, quality and purity) will be a decisive driving force, acting as a tool to refute some of the preconceptions about continuous systems and to be used as a reference for other projects.

\section{Acknowledgments}

This research work was supported by the grant SFRH/BPD/98694/ 2013 (Bruno Fernandes) from Fundação para a Ciência e a Tecnologia (Portugal). The authors thank the FCT Strategic Project PEst-OE/EQB/ LA0023/2013. The authors also thank the Project "BioInd-Biotechnology and Bioengineering for improved Industrial and Agro-Food processes, REF. NORTE-07-0124-FEDER-000028" Co-funded by the Programa Operacional Regional do Norte (ON.2-O Novo Norte), QREN, FEDER.

\section{References}

Abdollahi J, Dubljevic S. Lipid production optimization and optimal control of heterotrophic microalgae fed-batch bioreactor. Chem Eng Sci 2012;84:619-27.

Abdulqader G, Barsanti L, Tredici M. Harvest of Arthrospira platensis from Lake Kossorom (Chad) and its household usage among the Kanembu. J Appl Phycol 2000;12:493-8.

Acién FG, Fernández JM, Magán JJ, Grima EM. Production cost of a real microalgae production plant and strategies to reduce it. Biotechnol Adv 2012;30(6):1344-53.

Agrawal P, Koshy G, Ramseier M. An algorithm for operating a fed-batch fermentor at optimum specific-growth rate. Biotechnol Bioeng 1989;33(1):115-25.

Aiba S. Growth kinetics of photosyntethic microorganisms. Adv Biochem Eng 1982;23: 85-153.

Aksu Z. Biosorption of heavy metals by microalgae in batch and continuous systems. In: Wong Y-S, Tam NY, editors. Wastewater Treat with Algae SE-3. Springer Berlin Heidelberg; 1998. p. 37-53.

Alonso DL, Belarbi EH, Fernández-Sevilla JM, Rodríguez-Ruiz J, Grima EM. Acyl lipid composition variation related to culture age and nitrogen concentration in continuous culture of the microalga Phaeodactylum tricornutum. Phytochemistry 2000;54(5): 461-71.

Anderson TH, Brune DE. Continuous production of microalgae using a scouring film reactor. Aquac Eng 1982;1(3):205-14.

Aoyama I, Okamura H. Interactive toxic effect and bioconcentration between cadmium and chromium using continuous algal culture. Environ Toxicol Water Qual 1993; 8(3):255-69.

Balasubramanian S, Allen JD, Kanitkar A, Boldor D. Oil extraction from Scenedesmus obliquus using a continuous microwave system-design, optimization, and quality characterization. Bioresour Technol 2011;102(3):3396-403.

Banister TT. Quantitive description of steady state nutrient-saturated algal growth, including adaptation. Limnol Oceanogr 1979;24(1):76-96.

Baquerisse D, Nouals S, Isambert A, dos Santos PF, Durand G. Modelling of a continuous pilot photobioreactor for microalgae production. J Biotechnol 1999; 70(1-3):335-42. 
Barbosa MJ, Zijffers JW, Nisworo A, Vaes W, van Schoonhoven J, Wijffels RH. Optimization of biomass, vitamins, and carotenoid yield on light energy in a flat-panel reactor using the A-stat technique. Biotechnol Bioeng 2005;89(2):233-42.

Becerra-Celis G, Hafidi G, Tebbani S, Dumur D, Isamber A. Nonlinear predictive control for continuous microalgae cultivation process in a photobioreactor. 10th Intl Conf Control Autom Robot Vis. Hanoi, Vietnam; 2008. p. 1373-8.

Béchet Q, Shilton A, Guieysse B. Modeling the effects of light and temperature on algae growth: state of the art and critical assessment for productivity prediction during outdoor cultivation. Biotechnol Adv 2013;31(8):1648-63.

Behrens PW. Photobioreactors and fermentors: the light and dark sides of growing algae. In: Andersen RA, editor. Algal Cult TechAlgal Culturing Techniques. 1st ed. Burlington, USA: Elsevier Academic Press; 2005. p. 189-203.

Belarbi E, Grima EM, Chisti Y. A process for high yield and scaleable recovery of high purity eicosapentaenoic acid esters from microalgae and fish oil. Enzyme Microb Technol 2000;26(7):516-29.

Berenguel M, Rodríguez F, Acién FG, JL. Garćia. Model predictive control of pH in tubular photobioreactors. J Process Control 2004;14(4):377-87.

Blumwald E, Tel-or E. Salt adaptation of the cyanobacterium Synechoccus 6311 growing in a continuous culture (Turbidostast). Plant Physiol 1984;74:183-5.

Borowitzka LJ. Development of western biotechnology's algal $\beta$-carotene plant. Bioresour Technol 1991;38(2-3):251-2.

Borowitzka MA. Microalgae for aquaculture: opportunities and constraints. J Appl Phycol 1997;9(5):393-401.

Borowitzka MA. Commercial production of microalgae: ponds, tanks, tubes and fermenters. J Biotechnol 1999;70(1-3):313-21.

Borowitzka MA. Culturing microalgae in outdoor ponds. In: Andersen RA, editor. Algal culturing techniques. 1st ed. Burlington, USA: Elsevier Academic Press; 2005. p. 205-18.

Bosma R, Van Spronsen WA, Tramper J, Wijffels RH. Ultrasound, a new separation technique to harvest microalgae. J Appl Phycol 2003;15:143-54.

Bougaran G, Le Dean L, Lukomska E, Kaas R, Baron R. Transient initial phase in continuous culture of Isochrysis galbana affinis Tahiti. Aquat Living Resour 2003;16(4):389-94.

Bougaran G, Bernard O, Sciandra A. Modeling continuous cultures of microalgae colimited by nitrogen and phosphorus. J Theor Biol 2010;265(3):443-54.

Brányik T, Silva DP, Vicente AA, Lehnert R, e Silva JBA, Dostálek P, et al. Continuous immobilized yeast reactor system for complete beer fermentation using spent grains and corncobs as carrier materials. J Ind Microbiol Biotechnol 2006;33(12):1010-8.

Brányik T, Silva DP, Baszczyňski M, Lehnert R, JB. Almeida e Silva. A review of methods of low alcohol and alcohol-free beer production. J Food Eng 2012;108(4):493-506.

Brennan L, Owende P. Biofuels from microalgae-a review of technologies for production, processing, and extractions of biofuels and co-products. Renew Sustain Energy Rev 2010;14(2):557-77.

Brennan L, Owende P. Biofuels from microalgae: towards meeting advanced fuel standards. In: Lee JW, editor. Advanced biofuels and bioproducts SE-24. New York: Springer New York; 2013. p. 553-99.

Brethauer S, Wyman CE. Review: continuous hydrolysis and fermentation for cellulosic ethanol production. Bioresour Technol 2010;101(13):4862-74.

Brewer PG, Goldman JC. Alkalinity changes generated by phytoplankton. Limnol Oceanogr 1976;21(1):108-17.

Briassoulis D, Panagakis P, Chionidis M, Tzenos D, Lalos A, Tsinos C, et al. An experimental helical-tubular photobioreactor for continuous production of Nannochloropsis sp. Bioresour Technol 2010;101(17):6768-77.

Broneske J, Franke H, Hielscher H, Hinderberg T, Kruger K. Microorganisms removal method e.g. for removing micro alga films from bioreactors, involves applying ultrasonic power over outside surfaces of containers or reactors by means of Sonotrode, Patent DE 102005025118 A1, 2007.

Buehner M, Young P, Willson B, Rausen D, Schoonover R, Babbitt G, et al. Microalgae growth modeling and control for a vertical flat panel photobioreactor. Am Control Conf. St. Louis, MO; 2009. p. 2301-6.

Camacho F, Grima EM, Martinez ME, Sánchez S, Garcia F. Continuous culture of the marine microalga Tetraselm is sp .-productivity analysis. Aquaculture 1990;90:75-84.

Carlsson AS. Micro- and macro-algae: utility for industrial applications: outputs from the EPOBIO project. CPL Press; 2007. p. 82.

Carvalho AP, Malcata FX. Optimization of omega-3 fatty acid production by microalgae: crossover effects of $\mathrm{CO} 2$ and light intensity under batch and continuous cultivation modes. Mar Biotechnol 2005;7(4):381-8.

Carvalho AP, Meireles LA, Malcata FX. Microalgal reactors: a review of enclosed system designs and performances. Biotechnol Prog 2006;22(6):1490-506.

Castellanos CS. Batch and continuous studies of Chlorella vulgaris in photobioreactors. The University of Western Ontario; 2013. p. 80.

Červený J, Šetlík I, Trtílek M, Nedbal L. Photobioreactor for cultivation and real-time, insitu measurement of $\mathrm{O} 2$ and $\mathrm{CO} 2$ exchange rates, growth dynamics, and of chlorophyll fluorescence emission of photoautotrophic microorganisms. Eng Life Sci 2009; 9(3):247-53.

Chaumont D. Biotechnology of algal biomass production: a review of systems for outdoor mass culture. J Appl Phycol 1993;5(6):593-604.

Chaumont D, Thepenier C, Gudin C. Scaling up a tubular photoreactor for continuous culture of Porphyridium cruentum-from laboratory to pilot plant. In: Stadler T, Morillon J, Verdus M, Karamanos W, Morvan H, Christiaen D, editors. Algal biotechnology. London: Elsevier Applied Science; 1988. p. 199-208.

Chaumont D, Ferreira dos Santos P, Sauze L. Photobioréacteur avec un dispositif de nettoyage automatique et continu de la canalisation du récepteur solaire du photobioréacteur (in French). EP 0506568B1; 1992. p. 12.

Chen C-Y, Yeh K-L, Aisyah R, Lee D-J, Chang J-S. Cultivation, photobioreactor design and harvesting of microalgae for biodiesel production: a critical review. Bioresour Technol 2011;102(1):71-81.
Cheng-Wu Z, Zmora O, Kopel R, Richmond A. An industrial-size flat plate glass reactor for mass production of Nannochloropsis sp. (Eustigmatophyceae). Aquaculture 2001 195:35-49.

Chetsumon A, Maeda I, Umeda F, Yagi K, Miura Y, Mizoguchi T. Continuous antibiotic production by an immobilized cyanobacterium in a seaweed-type bioreactor. J Appl Phycol 1995; 7:135-9.

Chisti Y. Biodiesel from microalgae. Biotechnol Adv 2007;25(3):294-306

Choi S-L, Suh IS, Lee C-G. Lumostatic operation of bubble column photobioreactors for Haematococcus pluvialis cultures using a specific light uptake rate as a control parameter. Enzyme Microb Technol 2003;33(4):403-9.

Christenson L, Sims R. Production and harvesting of microalgae for wastewater treatment, biofuels, and bioproducts. Biotechnol Adv 2011;29(6):686-702.

Clarkson N, Jones KO, Young AJ. Modelling of a continuous algal production system using intelligent methods. In: Chen F, Jiang Y, editors. Algae their Biotechnol potential: 4th Asia-Pacific Conf Algal BiotechnolSpringer; 2001. p. 93-106.

Cohen E, Koren A, (Malis) Arad S. A closed system for outdoor cultivation of microalgae. Biomass and Bioenergy 1991;1(2):83-8.

Collins CM, Anderson AM, Weger HG. Iron acquisition by the green alga Selenastrum minutum: growth in iron-limited chemostats and effects of chelator stability constant. Arch für Hydrobiol 2001;151(2):283-99.

Cooney CL. Continuous culture or microorganims: an overview and prespective. Ann N Y Acad Sci 1979;326(1):295-314

Córdoba-Matson MV, Gutiérrez J, Porta-Gándara MÁ. Evaluation of Isochrysis galbana (clone T-ISO) cell numbers by digital image analysis of color intensity. J Appl Phyco 2009;22(4):427-34

Coustets M, Al-Karablieh N, Thomsen C, Teissié J. Flow process for electroextraction of total proteins from microalgae. J Membr Biol 2013;246(10):751-60.

Cuaresma M, Janssen M, Vílchez C, Wijffels RH. Productivity of Chlorella sorokiniana in a short light-path (SLP) panel photobioreactor under high irradiance. Biotechnol Bioeng 2009;104(2):352-9.

Cuaresma M, Janssen M, van den End EJ, Vílchez C, Wijffels RH. Luminostat operation: A tool to maximize microalgae photosynthetic efficiency in photobioreactors during the daily light cycle? Bioresour Technol 2011;102:7871-8.

Czitrom V. One-factor-at-a-time versus designed experiments. Am Stat 1999;53(2): 126-31.

D'Souza FML, Kelly GJ. Effects of a diet of a nitrogen-limited alga (Tetraselmis suecica) on growth, survival and biochemical composition of tiger prawn (Penaeus semisulcatus. Aquaculture 2000;181:311-29.

Dang TC, Fujii M, Rose AL, Bligh M, Waite TD. Characteristics of the freshwater cyanobacterium Microcystis aeruginosa grown in iron-limited continuous culture. Appl Environ Microbiol 2012;78(5):1574-83.

Davis R, Aden A, Pienkos PT. Techno-economic analysis of autotrophic microalgae for fuel production. Appl Energy 2011;88(10):3524-31.

De-Bashan LE, Moreno M, Hernandez J-P, Bashan Y. Removal of ammonium and phosphorus ions from synthetic wastewater by the microalgae Chlorella vulgaris coimmobilized in alginate beads with the microalgae growth-promoting bacterium Azospirillum brasilense. Water Res 2002;36(12):2941-8.

Del Campo JA, Rodríguez H, Moreno J, Vargas MA, Rivas J, Guerrero MG. Lutein production by Muriellopsis sp. in an outdoor tubular photobioreactor. J Biotechnol 2001;85(3): 289-95.

Del Río E, Acién FG, García-Malea MC, Rivas J, Grima EM, Guerrero MG. Efficient one-step production of astaxanthin by the microalga Haematococcus pluvialis in continuous culture. Biotechnol Bioeng 2005;91(7):808-15.

Doucha J, Lívanský K. Productivity, CO2/O2 exchange and hydraulics in outdoor open high density microalgal (Chlorella sp.) photobioreactors operated in a Middle and Southern European climate. J Appl Phycol 2006;18(6):811-26.

Doucha J, Straka F, Lívanský K. Utilization of flue gas for cultivation of microalgae Chlorella sp.) in an outdoor open thin-layer photobioreactor. J Appl Phycol 2005; 17(5):403-12.

Dragone G, Fernandes B, Vicente AA, Teixeira JA. Third generation biofuels from microalgae. In: Méndez-Vilas A, editor. Current research, technology and education topics in applied microbiology and microbial biotechnology. Badajoz: Formatex; 2010. p. 1355-66.

Dragone G, Fernandes BD, Abreu AP, Vicente AA, Teixeira JA. Nutrient limitation as a strategy for increasing starch accumulation in microalgae. Appl Energy 2011; 88(10):3331-5

Drapcho C, Brune D. The partitioned aquaculture system: impact of design and environmental parameters on algal productivity and photosynthetic oxygen production. Aquac Eng 2000;21:151-68.

Droop MR. Vitamin B12 and Marine Ecology III. An experiment with a chemostat. J Ma Biol Assoc United Kingdom 1966;46(03):659-71.

Droop MR. The kinetics of uptake growth and inhibition in Monochrysis lutheri. J Mar Bio Assoc United Kingdom 1968;48:686-733.

Dunstan W, Menzel D. Continuous cultures of natural populations of phytoplankton in dilute, treated sewage effluent. Limnol Oceanogr 1971;16(4):623-32.

Eriksen N, Poulsen B, Lønsmann Iversen JJ. Dual sparging laboratory-scale photobioreactor for continuous production of microalgae. J Appl Phycol 1998;10(4):377-82.

Fabregas J, Herrero C, Cabezas B, Abalde J. Biomass production and biochemical composition in mass cultures of the marine microalga Isochrysis galbana Parke at varying nutrient concentrations. Aquaculture 1986;53(2):101-13.

Falkowski PG, Raven JA. Aquatic photosynthesis. In: Falkowski PG, Raven JA, editors. 2nd ed. Princeton: Princeton University Press; 2007. p. 488.

Fernandes B, Teixeira J, Dragone G, Vicente AA, Kawano S, Bišová K, et al. Relationship between starch and lipid accumulation induced by nutrient depletion and replenishment in the microalga Parachlorella kessleri. Bioresour Technol 2013; $144: 268-74$. 
Fernandes BD, Mota A, Ferreira A, Dragone G, Teixeira JA, Vicente AA. Characterization of split cylinder airlift photobioreactors for efficient microalgae cultivation. Chem Eng Sci 2014; 117:445-54.

Fernandez F, Camacho F, Perez J, Sevilla J, Grima EM. Modeling of biomass productivity in tubular photobioreactors for microalgal cultures: effects of dilution rate, tube diameter, and solar irradiance. Biotechnol Bioeng 1998;58(6):605-16.

Fernández FA, Sevilla JMF, Pérez JAS, Grima EM, Chisti Y. Airlift-driven external-loop tubular photobioreactors for outdoor production of microalgae: assessment of design and performance. Chem Eng Sci 2001;56:2721-32.

Fernández FGA, Fernández Sevilla JM, Molina Grima E. Microalgal biotechnology: potential and production. In: Posten C, Walter C, editors. Principles of photobioreactor design. Berlin: De Gruyter; 2012

Fernandez I, Acien FG, Berenguel M, Guzmán JL. First principles model of a tubular photobioreactor for microalgal production. Ind Eng Chem Res 2014;53:11121-36.

Fernández-Sevilla JM, Acién-Fernández FG, Molina-Grima E. Photobioreactors desig for hydrogen production. In: Zannoni D, De Philippis R, editors. Microbial bioenergy: hydrogen production, Vol. 38. Advances in Photosynthesis and Respiration; 2014.

Ferreira EMFC, Teixeira JA. Bioreactores. In: Lima N, Mota M, editors. Biotecnologia: Fundamentos e Aplicações (in Portuguese). Lisboa: Lidel Edições Técnicas; 2003. p. 165-94.

Fiechter A. Continuous cultivation of yeasts. In: Prescott DM, editor. Methods in cell biology, vol. 11. Elsevier Inc.; 1975. p. 97-130.

Fonseca MM, Teixeira JA. Reactores Biológicos-Fundamentos e Aplicações. In: Fonseca MM, Teixeira JA, editors. Lisboa: Lidel Edições Técnicas; 2007. p. 483.

Fuentes MMR, Sánchez JLG, Sevilla JMF, Acién Fernández FG, Pérez JAS, Grima EM. Outdoor continuous culture of Porphyridium cruentum in a tubular photobioreactor: quantitative analysis of the daily cyclic variation of culture parameters. J Biotechnol 1999;70:271-88.

Ganuza E, Izquierdo MS. Lipid accumulation in Schizochytrium G13/2S produced in continuous culture. Appl Microbiol Biotechnol 2007;76(5):985-90.

Garbisu C, Gil J, Bazin M, Hall D, Serra JL. Removal of nitrate from water by foamimmobilized Phormidium laminosum in batch and continuous-flow bioreactors. Appl Phycol 1991;3:221-34.

García-Malea MC, Acién FG, Del Río E, Fernández JM, Cerón MC, Guerrero MG, et al. Production of astaxanthin by Haematococcus pluvialis: taking the one-step system outdoors. Biotechnol Bioeng 2009;102(2):651-7.

Gauthier D, Turpin D. Interactions between inorganic phosphate (Pi) assimilation, photosynthesis and respiration in the Pi-limited green alga Selenastrum minutum. Plant Cel Environ 1997:20:12-24.

Gobel F. Quantum efficiencies of growth. In: Claytons KR, Sistrom WR, editors. Photosynthetic bacteria. New York: Plenum Press; 1978. p. 90-25.

Goettel M, Eing C, Gusbeth C, Straessner R, Frey W. Pulsed electric field assisted extraction of intracellular valuables from microalgae. Algal Res 2013;2(4):401-8.

Goffaux G, Vande Wouwer A, Bernard O. Continuous-discrete interval observers for monitoring microalgae cultures. Am Inst Chem Eng 2009;25(3):667-75.

González-López CV, Acién Fernández FG, Fernández-Sevilla JM, Sánchez Fernández JF, Grima EM. Development of a process for efficient use of $\mathrm{CO} 2$ from flue gases in the production of photosynthetic microorganisms. Biotechnol Bioeng 2012;109(7): $1637-50$

Gouveia L, Marques AE, da Silva TL, Reis A. Neochloris oleabundans UTEX \#1185: a suitable renewable lipid source for biofuel production. J Ind Microbiol Biotechnol 2009; 36(6):821-6.

Gress CD, Treble RG, Matz CJ, Weger HG. Biological availability of iron to the freshwate cyanobacterium Anabaena Flos-Aquae1. J Phycol 2004;40(5):879-86.

Grima EM, Medina A, Giménez A. Comparison between extraction of lipids and fatty acids from microalgal biomass. J Am Oil Chem Soc 1994;71(9):955-9.

Grima EM, Fernández FGA, Medina AR. Downstream processing of cell-mass and products. In: Richmond A, editor. Handbook of microalgal culture: biotechnology and ap plied phycology. Oxford: Blackwell Publishing Ltd; 2004. p. 215-51.

Guedes AC, Amaro HM, Malcata FX. Microalgae as sources of carotenoids. Mar Drugs 2011:9(4):625-44.

Guedes AC, Katkam NG, Varela J, Malcata FX. Photobioreactors for cyanobacterial culturing. In: Sharma NK, Rai AK, Stal LJ, editors. Cyanobacteria: an economic prespective. Chischester. UK: John Wiley \& Sons, Ltd; 2014. p. 270-92.

Gutierrez-Wing MT, Benson BC, Rusch KA. Impact of light quality and quantity on growth rate kinetics of Selenastrum capricornutum. Eng Life Sci 2012;12(1):79-88.

Hagstrom JA, Graneli E, Moreira MOP, Odebrecht C. Domoic acid production and elemental composition of two Pseudo-nitzschia multiseries strains, from the NW and SW Atlantic Ocean, growing in phosphorus- or nitrogen-limited chemostat cultures. J Plankton Res 2010;33(2):297-308.

Hall DO, Fernández FGA, Guerrero EC, Rao KK, Grima EM. Outdoor helical tubular photobioreactors for microalgal production: modeling of fluid-dynamics and mass transfer and assessment of biomass productivity. Biotechnol Bioeng 2003;82(1): 62-73.

Harrison STL, Richardson C, Griffiths MJ. Analysis of microalgal biorefineries for bioenergy from an environmental and economic perspective focus on algal biodiesel. In: Bux F editor. Biotechnological applications of microalgae. CRC Press; 2013. p. 113-36.

Harun R, Davidson M, Doyle M, Gopiraj R, Danquah M, Forde G. Technoeconomic analysis of an integrated microalgae photobioreactor, biodiesel and biogas production facility. Biomass and Bioenergy 2011;35(1):741-7.

Havlik I, Lindner P, Scheper T, Reardon KF. On-line monitoring of large cultivations of microalgae and cyanobacteria. Trends Biotechnol 2013a;31(7):406-14.

Havlik I, Reardon KF, Ünal M, Lindner P, Prediger A, Babitzky A, et al. Monitoring of microalgal cultivations with on-line, flow-through microscopy. Algal Res 2013b; 2(3):253-7.
Heasman M, Diemar J, O'Connor W, Foulkes L. Development of extended shelf-life microalgae concentrate diets harvested by centrifugation for bivalve molluscs-a summary. Aquac Res 2000;31(1989):637-59.

Hoskisson PA, Hobbs G. Continuous culture-making a comeback? Microbiology 2005; 151(Pt 10):3153-9.

Hu Q. Environmental effects on cell composition. In: Richmond A, editor. Handbook of microalgal culture: biotechnology and applied phycology. Oxford: Blackwell Science Ltd; 2004. p. 83-93.

Hulatt CJ, Thomas DN. Productivity, carbon dioxide uptake and net energy return of microalgal bubble column photobioreactors. Bioresour Technol 2011;102(10): 5775-87.

Iehana M. Kinetic analysis of the growth of Spirulina sp. on continuous culture. J Ferment Technol 1983;61(5):457-66.

Ifrim G, Titica M, Cogne G, Boillereaux L, Legrand J, Caraman S. Dynamic pH model for autotrophic growth of microalgae in photobioreactor: a tool for monitoring and control purposes. AIChE J 2014;60(2):585-99.

Imaizumi Y, Nagao N, Yusoff FM, Taguchi S, Toda T. Estimation of optimum specific light intensity per cell on a high-cell-density continuous culture of Chlorella zofingiensis not limited by nutrients or $\mathrm{CO}_{2}$. Bioresour Technol 2014;162:53-9.

Jácome-Pilco CR, Cristiani-Urbina E, Flores-Cotera LB, Velasco-García R, Ponce-Noyola T, Cañizares-Villanueva RO. Continuous $\mathrm{Cr}(\mathrm{VI})$ removal by Scenedesmus incrassatulus in an airlift photobioreactor. Bioresour Technol 2009;100(8):2388-91.

James CM, Al-Khars AM. An intensive continuous culture system using tubular photobioreactors for producing microalgae. Aquaculture 1990;87:381-93.

Janssen M, Tramper J, Mur LR, Wijffels RH. Enclosed outdoor photobioreactors: light regime, photosynthetic efficiency, scale-up, and future prospects. Biotechnol Bioeng 2003;81(2):193-210.

Jaramillo JJ, Naranjo JM, Cardona CA. Growth and oil extraction from Chlorella vulgaris: a techno-economic and environmental assessment. Ind Eng Chem Res 2012;51: 10503-8.

Javanmardian M, Palsson BO. Continuous photoautotrophic cultures of the eukaryotic alga Chlorella vulgaris can exhibit stable oscillatory dynamics. Biotechnol Bioeng 1992; 39(5):487-97.

Jung S-K, Lee SB. In situ monitoring of cell concentration in a photobioreactor using image analysis: comparison of uniform light distribution model and artificial neural networks. Biotechnol Prog 2006;22(5):1443-50.

Jungbauer A. Continuous downstream processing of biopharmaceuticals. Trends Biotechnol 2013;31(8):479-92.

Kim J, Ryu B-G, Kim K, Kim B-K, Han J-I, Yang J-W. Continuous microalgae recovery using electrolysis: effect of different electrode pairs and timing of polarity exchange. Bioresour Technol 2012;123:164-70.

Kim J, Yoo G, Lee H, Lim J, Kim K, Kim CW, et al. Methods of downstream processing for the production of biodiesel from microalgae. Biotechnol Adv 2013;31(6):862-76.

Kim J, Ryu B-G, Lee Y-J, Han J-I, Kim W, Yang J-W. Continuous harvest of marine microalgae using electrolysis: effect of pulse waveform of polarity exchange. Bioprocess Biosyst Eng 2014;37(7):1249-59.

Kleinegris DMM, Janssen M, Brandenburg WA, Wijffels RH. Continuous production of carotenoids from Dunaliella salina. Enzyme Microb Technol 2011;48(3):253-9.

Klok AJ, Martens DE, Wijffels RH, Lamers PP. Simultaneous growth and neutral lipid accumulation in microalgae. Bioresour Technol 2013a;134:233-43.

Klok AJ, Verbaanderd JA, Lamers PP, Martens DE, Rinzema A, Wijffels RH. A model for customising biomass composition in continuous microalgae production. Bioresour Technol 2013b;146:89-100.

Kumar D, Rai J, Gaur JP. Removal of metal ions by Phormidium bigranulatum (cyanobacteria)-dominated mat in batch and continuous flow systems. Bioresour Technol 2012;104:202-7.

Kunjapur AM, Eldridge RB. Photobioreactor design for commercial biofuel production from microalgae. Ind Eng Chem Res 2010;49(8):3516-26.

Kwon J-H, Rögner M, Rexroth S. Direct approach for bioprocess optimization in a continuous flat-bed photobioreactor system. J Biotechnol 2012;162(1):156-62.

Lamers PP, van de Laak CCW, Kaasenbrood PS, Lorier J, Janssen M, De Vos RCH, et al. Carotenoid and fatty acid metabolism in light-stressed Dunaliella salina. Biotechnol Bioeng 2010;106(4):638-48.

Lee PG. A review of automated control systems for aquaculture and design criteria for their implementation. Aquac Eng 1995;14(3):205-27.

Lee Y-K, Ding S-Y. Cell cycle and accumulation of astaxanthin in Haematococcus lacustris (Chlorophyta). J Phycol 1994;30(3):445-9.

Lee Y-K, Shen H. Basic culturing techniques. In: Richmond A, editor. Handbook of microalgal culture: biotechnology and applied phycology. Oxford: Blackwell Science Ltd; 2004. p. 40-56.

Lee Y-K, Soh C-W. Accumulation of astaxanthin in Haematococcus lacustris (Chlorophyta). J Phycol 1991;27(5):575-7.

Lee AK, Lewis DM, Ashman PJ. Energy requirements and economic analysis of a full-scale microbial flocculation system for microalgal harvesting. Chem Eng Res 2010;88(8): 988-96.

Lee Y-K, Chen W, Shen H, Han D, Li Y, Jones HDT, et al. Basic culturing and analytical measurement techniques Yuan-Kun. In: Richmond A, Hu Q editors. Handbook microalgal culture: biotechnol and applied phycology. Oxford: Wiley Blackwell; 2013. p. 37-68.

Li J, Xu NS, Su WW. Online estimation of stirred-tank microalgal photobioreactor cultures based on dissolved oxygen measurement. Biochem Eng J 2003;14(1):51-65.

Li J, Zhu D, Niu J, Shen S, Wang G. An economic assessment of astaxanthin production by large scale cultivation of Haematococcus pluvialis. Biotechnol Adv 2011a;29(6): 568-74.

Li Y, Chen Y-F, Chen P, Min M, Zhou W, Martinez B, et al. Characterization of a microalga Chlorella sp. well adapted to highly concentrated municipal wastewater for nutrient removal and biodiesel production. Bioresour Technol 2011b;102(8):5138-44. 
Lindberg P, Park S, Melis A. Engineering a platform for photosynthetic isoprene production in cyanobacteria, using Synechocystis as the model organism. Metab Eng 2010; 12(1):70-9.

Lívanský K, Doucha J, Hu H, Li Y. CO2 partial pressure-pH relationships in the medium and relevance to $\mathrm{CO} 2$ mass balance in outdoor open thin-layer Arthrospira (Spirulina) cultures. Arch für Hydrobiol 2006;165(3):365-81.

López MCG-M, Sánchez EDR, López JLC, Fernández FGA, Sevilla JMF, Rivas J, et al. Comparative analysis of the outdoor culture of Haematococcus pluvialis in tubular and bubble column photobioreactors. J Biotechnol 2006;123(3):329-42.

Loubière K, Olivo E, Bougaran G, Pruvost J, Robert R, Legrand J. A new photobioreactor for continuous microalgal production in hatcheries based on external-loop airlift and swirling flow. Biotechnol Bioeng 2009;102(1):132-47.

Lyck S, Gjølme N, Utkilen H. Iron starvation increases toxicity of Microcystis aeruginosa CYA 228/1 (Chroococcales, Cyanophyceae). Phycologia 1996;35(6):120-4.

Macintyre HL, Cullen JJ. Using cultures to investigate the physiological ecology of microalgae. In: Andersen RA, editor. Algal culturing techniques. Burlington, USA: Elsevier Academic Press; 2005. p. 287-326.

Madhyastha HK, Vatsala TM. Pigment production in Spirulina fussiformis in different photophysical conditions. Biomol Eng 2007;24(3):301-5.

Maeda I, Seto Y, Ueda S, Cheng Y, Hari J, Kawase M, et al. Simultaneous control of turbidity and dilution rate through adjustment of medium composition in semi-continuous Chlamydomonas cultures. Biotechnol Bioeng 2006:94(4):722-9.

Mairet F, Bernard O, Masci P, Lacour T, Sciandra A. Modelling neutral lipid production by the microalga Isochrysis aff. galbana under nitrogen limitation. Bioresour Technol 2011;102(1):142-9.

Marchetti J, Bougaran G, Le Dean L, Mégrier C, Lukomska E, Kaas R, et al. Optimizing conditions for the continuous cultura of Isochrysis affinis galbana relevant to commercial hatcheries. Aquaculture 2012;326-329:106-15.

Markou G, Nerantzis E. Microalgae for high-value compounds and biofuels production: a review with focus on cultivation under stress conditions. Biotechnol Adv 2013;31(8): 1532-42.

Markov S. A hollow fibre photobioreactor for continuous production of hydrogen by immobilized cyanobacteria under partial vacuum. Int J Hydrogen Energy 1993: 18(11):901-6.

Martinez Sancho ME, Jimenez Castillo JM, Espinola Lozano JB, El Yousfi F. Sistemas AlgasBacterias para Tratamiento de Residuos Liquidos (in Spanish). Ing Quim 1993;25: 131-5.

Marzocchella A, Andreozzi R, Bartalini G, Filippone E, Olivieri G, Pinto G, et al. A technoeconomic assessment of biofuels production by microalgae. Chem Eng Trans 2010; 20:169-74.

Masojídek J, Sergejevová M, Rottnerová K, Jirka V, Korečko J, Kopecký J, et al. A two-stage solar photobioreactor for cultivation of microalgae based on solar concentrators. J Appl Phycol 2008:21(1):55-63.

Mata TM, Martins AA, Caetano NS. Microalgae for biodiesel production and other applications: a review. Renew Sustain Energy Rev 2010;14(1):217-32.

McGinn PJ, Dickinson KE, Park KC, Whitney CG, MacQuarrie SP, Black FJ, et al. Assessment of the bioenergy and bioremediation potentials of the microalga Scenedesmus sp. AMDD cultivated in municipal wastewater effluent in batch and continuous mode. Algal Res 2012;1(2):155-65.

Meireles LA, Guedes AC, Barbosa CR, Azevedo JL, Cunha JP, Malcata FX. On-line control of light intensity in a microalgal bioreactor using a novel automatic system. Enzyme Microb Technol 2008;42(7):554-9.

Meiser A, Schmid-Staiger U, Trosch W. Optimization of eicosapentaenoic acid production by Phaeodactylum tricornutum in the flat panel airlift (FPA) reactor. J Appl Phycol 2004; $16: 215-25$

Mendes-Pinto MM, Raposo MFJ, Bowen J, Young AJ, Morais R. Evaluation of different cell disruption processes on encysted cells of Haematococcus pluvialis: effects on astaxanthin recovery and implications for bio-availability. J Appl Phycol 2001;13: 19-24.

Middlemiss JK, Anderson AM, Stratilo CW, Weger HG. Oxygen consumption associated with ferric reductase activity and iron uptake by iron-limited cells of Chlorella kessleri (Chlorophyceae). J Phycol 2001;37(3):393-9.

Mirón AS, Garćla MCC, Gómez AC, Camacho FG, Grima EM, Chisti Y. Shear stress tolerance and biochemical characterization of Phaeodactylum tricornutum in quasi steady-state continuous culture in outdoor photobioreactors. Biochem Eng J 2003;16(3):287-97.

Mock CR, Murphy MA. Techniques for raising penaeid shrimp from the egg to postlarvae1. Proc Annu Work-World Maric Soc 1970;1(1-4):141-56.

Molina Grima E, Fernández FGA, Garćia Camacho F, Chisti Y. Photobioreactors: light regime, mass transfer, and scaleup. J Biotechnol 1999;70:231-47.

Molina Grima E, Fernández J, Acién FG, Chisti Y. Tubular photobioreactor design for algal cultures. J Biotechnol 2001;92(2):113-31.

Molina Grima E, Belarbi E-H, Acién Fernández FG, Robles Medina A, Chisti Y. Recovery of microalgal biomass and metabolites: process options and economics. Biotechnol Adv 2003;20(7-8):491-515.

Molina-Grima E, Camacho FG, Sánchez Pérez JA, Sevilla JMF, Fernandez FGA, Gomez AC. A mathematical model of microalgal growth in light-limited chemostat culture. J Chem Technol Biotechnol 1994;61:167-73.

Molinuevo-Salces B, García-González MC, González-Fernández C. Performance comparison of two photobioreactors configurations (open and closed to the atmosphere) treating anaerobically degraded swine slurry. Bioresour Technol 2010;101(14): 5144-9.

Monod J. La technique de culture continue, theorie et applications. Ann d'Institute Pasteur 1950;79:390-410.

Moreno J, Vargas MA, Olivares H, Rivas J, Guerrero MG. Exopolysaccharide production by the cyanobacterium Anabaena sp. ATCC 33047 in batch and continuous culture. J Biotechnol 1998;60(3):175-82.
Moreno-Garrido I. Microalgae immobilization: current techniques and uses. Bioresour Technol 2008;99:3949-64.

Morist A, Montesinos J, Cusidó J, Gòdia F. Recovery and treatment of Spirulina platensis cells cultured in a continuous photobioreactor to be used as food. Process Biochem 2001;37(5):535-47.

Muller-Feuga A, Guédes RL, Hervé A, Durand P. Comparison of artificial light photobioreactors and other production systems using Porphyridium cruentum. J Appl Phycol 1998;10:83-90.

Muñoz R, Guieysse B. Algal-bacterial processes for the treatment of hazardous contaminants: a review. Water Res 2006;40(15):2799-815.

Muñoz R, Köllner C, Guieysse B, Mattiasson B. Photosynthetically oxygenated salicylate biodegradation in a continuous stirred tank photobioreactor. Biotechnol Bioeng 2004;87(6):797-803.

Myers J, Clark LB. Culture conditions and the development of the photosynthetic mechanism. II. An apparatus for the continuous culture of Chlorella. J Gen Physiol 1944;28: 103-22.

Myers J, Graham J. On the mass culture of algae. II. Yield as a function of cell concentration under continuous sunlight irradiance. Plant Physiol 1958;34:345-52.

Nedbal L, Trtílek M, Cervený J, Komárek O, Pakrasi HB. A photobioreactor system for precision cultivation of photoautotrophic microorganisms and for high-content analysis of suspension dynamics. Biotechnol Bioeng 2008;100(5):902-10.

Nedbal L, Cervený J, Keren N, Kaplan A. Experimental validation of a nonequilibrium model of $\mathrm{CO}_{2}$ fluxes between gas, liquid medium, and algae in a flat-panel photobioreactor. J Ind Microbiol Biotechnol 2010;37(12):1319-26.

Niederholtmeyer H, Wolfstädter BT, Savage DF, Silver PA, Way JC. Engineering cyanobacteria to synthesize and export hydrophilic products. Appl Environ Microbiol 2010;76(11):3462-6.

Niedermeyer THJ, Kuchmina E, Wilde A. Engineering cyanobacteria for industrial products. In: Sharma NK, Rai AK, Stal LJ, editors. Cyanobacteria: an economic prespective. Chischester, UK: John Wiley \& Sons, Ltd; 2014. p. 303-18.

Novick A, Szilard L. Description of the Chemostat. Sci 1950;112(2920):715-6

Obata M, Toda T, Taguchi S. Using chlorophyll fluorescence to monitor yields of microalgal production. J Appl Phycol 2008;21(3):315-9.

Olaizola M. Commercial production of astaxanthin from Haematococcus pluvialis using 25,000-liter outdoor photobioreactors. J Appl Phycol 2000;12:499-506.

Palmer FE, Ballard KA, Taub FB. A continuous culture apparatus for the mass production of algae. Aquaculture 1975;6:319-31.

Paulová L, Patáková P, Brányik T. Advanced fermentation processes. In: Teixeira JA, Vicente AA, editors. Engineering aspects of food biotechnology. CRC Press; 2013. p. 89-110.

Peña-Castro JM, Martínez-Jerónimo F, Esparza-García F, Cañizares-Villanueva RO. Heavy metals removal by the microalga Scenedesmus incrassatulus in continuous cultures. Bioresour Technol 2004;94(2):219-22.

Pienkos PT. Historical overview of algal biofuel technoeconomic analyses. National Algal Biofuels Technology Roadmap Workshop; 2008. p. 23.

Pires EJ, Teixeira JA, Brányik T, Côrte-Real M, Vicente AA. Maintaining yeast viability in continuous primary beer fermentation. J Inst Brew 2014:8(120(1)):52-9.

Pirt SJ, Lee Y-K, Richmond A, Pirt MW. The photosynthetic efficiency of Chlorella biomass growth with reference to solar energy utilisation. J Chem Technol Biotechnol 1980 30(1):25-34.

Pistorius AMA, DeGrip WJ, Egorova-Zachernyuk TA. Monitoring of biomass composition from microbiological sources by means of FT-IR spectroscopy. Biotechnol Bioeng 2009;103(1):123-9.

Post F, Borowitzka L, Borowitzka M, Mackay B, Moulton T. The protozoa of a Western Australian hypersaline lagoon. Hydrobiologia 1983;105:95-113.

Posten C. Design principles of photo-bioreactors for cultivation of microalgae. Eng Life Sci 2009;9(3):165-77.

Powell EE, Hill GA. Economic assessment of an integrated bioethanol-biodiesel-microbia fuel cell facility utilizing yeast and photosynthetic algae. Chem Eng Res Des 2009; 87(9):1340-8

Pradhan S, Rai L. Optimization of flow rate, initial metal ion concentration and biomass density for maximum removal of $\mathrm{Cu} 2+$ by immobilized Microcystis. World J Microbiol Biotechnol 2000;16(6):579-84.

Pruvost J, Van Vooren G, Le Gouic B, Couzinet-Mossion A, Legrand J. Systematic investigation of biomass and lipid productivity by microalgae in photobioreactors for biodiesel application. Bioresour Technol 2011;102(1):150-8.

Pulz O, Scheibenbogen K, Grob W. Biotechnology with cyanobacteria and microalgae. In: Rehm H-J, Reed G, editors. Biotechnology second, completely. Revised ed. Weinheim: Wiley-VCH Verlag; 2001. p. 105-36.

Quesnel LB. Sterilization and sterility. In: Bu'Lock J, Kristiansen B, editors. New York Academc Press Inc; 1987. p. 197-215.

Quinn J, de Winter L, Bradley T. Microalgae bulk growth model with application to industrial scale systems. Bioresour Technol 2011;102(8):5083-92.

Rai PK, Tripathi BD. Removal of heavy metals by the nuisance cyanobacteria Microcystis in continuous cultures: an eco-sustainable technology. Environ Sci 2007;4(1):53-9.

Rebolloso Fuentes MM, Garćia Sánchez JL, Fernández Sevilla JM, Acién Fernández FG, Sánchez Pérez JA, Grima EM. Outdoor continuous culture of Porphyridium cruentum in a tubular photobioreactor: quantitative analysis of the daily cyclic variation of culture parameters. J Biotechnol 1999;70(1-3):271-88.

Reis A, Gouveia L, Veloso V, Fernandes HL, Empis JA, Novais JM. Eicosapentaenoic acidrich biomass production by the microalga Phaeodactylum tricornutum in a continuous-flow reactor. Bioresour Technol 1996;8524(95):83-8.

Rhee GY, Gotham IJ, Chisholm SW. Use of cyclostat cultures to study phytoplankton ecology. In: Calcott PH, editor. Continuous culture of cells, vol. II. Boca Raton: CRC Press; 1981. p. 159-87. 
Richmond A. Biological principles of mass cultivation of photoautotrophic microalgae. In: Richmond A, Hu Q, editors. Handbook microalgal culture: biotechnol and applied phycology. Oxford: Wiley Blackwell; 2013. p. 171-204.

Richmond A, Karg S, Boussiba S. Effects of bicarbonate and carbon dioxide on the competition between Chlorella vulgaris and Spirulina platensis. Plant Cell Physiol 1982;23(8): 1411-7.

Rodolfi L, Chini Zittelli G, Bassi N, Padovani G, Biondi N, Bonini G, et al. Microalgae for oil: strain selection, induction of lipid synthesis and outdoor mass cultivation in a lowcost photobioreactor. Biotechnol Bioeng 2009;102(1):100-12.

Rosenberg JN, Mathias A, Korth K, Betenbaugh MJ, Oyler GA. Microalgal biomass production and carbon dioxide sequestration from an integrated ethanol biorefinery in Iowa: a technical appraisal and economic feasibility evaluation. Biomass and Bioenergy 2011;35(9):3865-76.

Rossignol N, Vandanjon L, Jaouen P, Quéméneur F. Membrane technology for the continuous separation microalgae/culture medium: compared performances of cross-flow microfiltration and ultrafiltration. Aquac Eng 1999;20(3):191-208.

Ruiz J, Álvarez-Díaz PD, Arbib Z, Garrido-Pérez C, Barragán J, Perales JA. Performance of a flat panel reactor in the continuous culture of microalgae in urban wastewater: prediction from a batch experiment. Bioresour Technol 2013;127:456-63.

Rusch KA, Christensen JM. The hydraulically integrated serial turbidostat algal reactor (HISTAR) for microalgal production. Aquac Eng 2003;27(4):249-64.

Safi C, Ursu AV, Laroche C, Zebib B, Merah O, Pontalier P-Y, et al. Aqueous extraction of proteins from microalgae: effect of different cell disruption methods. Algal Res 2014;3:61-5.

Samson R, Leduy A. Multistage continuous cultivation of blue-green alga Spirulina maxima in the flat tank photobioreactors with recycle. Can J Chem Eng 1985;63(1):105-12.

San Pedro A, González-López CV, Acién FG, Grima EM. Marine microalgae selection and culture conditions optimization for biodiesel production. Bioresour Technol 2013; 134:353-61.

Sananurak C, Lirdwitayaprasit T, Menasveta P. Development of a closed-recirculating, continuous culture system for microalga (Tetraselmis suecica) and rotifer (Brachionus plicatilis) production. Sci Asia 2009;35:118-24.

Sandnes JM, Ringstad T, Wenner D, Heyerdahl PH, Källqvist T, Gislerød HR. Real-time monitoring and automatic density control of large-scale microalgal cultures using near infrared (NIR) optical density sensors. J Biotechnol 2006;122(2):209-15.

Sassano CEN, Gioielli LA, Almeida KA, Sato S, Perego P, Converti A, et al. Cultivation of Spirulina platensis by continuous process using ammonium chloride as nitrogen source. Biomass and Bioenergy 2007;31(8):593-8

Sassano CEN, Gioielli LA, Ferreira LS, Rodrigues MS, Sato S, Converti A, et al. Evaluation of the composition of continuously-cultivated Arthrospira (Spirulina) platensis using ammonium chloride as nitrogen source. Biomass and Bioenergy 2010;34(12):1732-8.

Scherholz ML, Curtis WR. Achieving pH control in microalgal cultures through fed-batch addition of stoichiometrically-balanced growth media. BioMed Cent Biotechnol 2013;13(39):1-17.

Sforza E, Enzo M, Bertucco A. Design of microalgal biomass production in a continuous photobioreactor: an integrated experimental and modeling approach. Chem Eng Res Des 2014;92(6):1153-62.

Sharma NK, Stal LJ. The economics of cyanobacteria-based biofuel production: challenges and opportunities. In: Sharma NK, Rai AK, Stal LJ, editors. Cyanobacteria: an economic prespective. Chischester, UK: John Wiley \& Sons, Ltd; 2014. p. 167-80.

Shelef G, Sukenik A, Green M. Microalgae harvesting and processing: a literature review. Report for US Department of Energy; 1984. p. 71

Shozen K, Umeda I, Nakashima T, Honma A. Continuous cultivation of a diatom, Chaetoceros ceratosporum, in deep-sea water pumped from Tomyama bay. IOA Newsl 2014;12(4):1-5.

Sim T-S, Goh A, Becker EW. Comparison of centrifugation, dissolved air flotation and drum filtration techniques for harvesting sewage-grown algae. Biomass 1988; 16(1):51-62.

Sobczuk TM, Chisti Y. Potential fuel oils from the microalga Choricystis minor. J Chem Technol Biotechnol 2010;85(1):100-8.

Sonier MB, Weger HG. Plasma membrane ferric reductase activity of iron-limited algal cells is inhibited by ferric chelators. Biometals 2010;23(6):1029-42.

Spolaore P, Joannis-Cassan C, Duran E, Isambert A. Commercial applications of microalgae. J Biosci Bioeng 2006;101(2):87-96.

Su WW, Li J, Xu N-S. State and parameter estimation of microalgal photobioreactor cultures based on local irradiance measurement. J Biotechnol 2003;105(1-2):165-78.

Su CM, Hsueh HT, Chen HH, Chu H. Effects of dissolved inorganic carbon and nutrient levels on carbon fixation and properties of Thermosynechococcus sp. in a continuous system. Chemosphere 2012;88(6):706-11.

Sun A, Davis R, Starbuck M, Ben-Amotz A, Pate R, Pienkos PT. Comparative cost analysis of algal oil production for biofuels. Energy 2011;36(8):5169-79.

Sundström H. Analytical tools for monitoring and control of fermentation processes. In: Sundström H, editor. Stockholm: Royal Institute of Technology; 2007. p. 70.

Takache H, Christophe G, Cornet J-F, Pruvost J. Experimental and theoretical assessment of maximum productivities for the microalgae Chlamydomonas reinhardtii in two different geometries of photobioreactors. Am Inst Chem Eng 2010;26(2):431-40.
Tang H, Chen M, Simon Ng KY, Salley SO. Continuous microalgae cultivation in a photobioreactor. Biotechnol Bioeng 2012;109(10):2468-74.

Thein M. Production of Spirulina in Myanmar (Burma). Bull Inst Ocean 1993;12:175-8.

Toroghi MK, Goffaux G, Perrier M. Output feedback passivity-based controller for microalgae cultivation. 12th IFAC Symp Comput Appl Biotechnol. Mumbai, India: The International Federation of Automatic Control; 2013. p. 16-8.

Tredici M. Bioreactors, photo. In: Flickinger M, Drew S, editors. Encyclopedia of bioprocess technology: fermentation, biocatalysis and bioseparation. New York: John Wiley \& Sons; 1999. p. 409-19.

Tredici M. Mass production of microalgae: photobioreactors. In: Richmond A, editor. Handbook of microalgal culture: biotechnology and applied phycology. Oxford: Blackwell Science Ltd; 2004. p. 178-214.

Trotta P. A simple and inexpensive system for continuous monoxenic mass culture of marine microalgae. Aquaculture 1981;22:383-7.

Tsygankov A, Hall D, Liu J, Rao KK. An automated helical photobioreactor incorporating cyanobacteria for continuous hydrogen production. In: Zaborsky O, Benemann J, Matsunaga T, Miyake J, San Pietro A, editors. BioHydrogen SE-52. US: Springer; 1998. p. 431-40.

Tuantet K, Temmink H, Zeeman G, Janssen M, Wijffels RH, Buisman CJN. Nutrient removal and microalgal biomass production on urine in a short light-path photobioreactor. Water Res 2014;55:162-74.

Tzovenis I, De Pauw N, Sorgeloos P. Optimisation of T-ISO biomass production rich in essential fatty acids. Aquaculture 2003;216(1-4):203-22.

Utkilen H, Gjølme N. Toxin production by Microcystis aeruginosa as a function of light in continuous cultures and its ecological significance. Appl Environ Microbiol 1992; 58(4):1321-5.

Utkilen H, Gjølme N. Iron-stimulated toxin production in Microcystis aeruginosa. Appl Environ Microbiol 1995;61(2):797-800.

Valenzuela-Espinoza E, Millán-Núñez R, Núñez-Cebrero F. Biomass production and nutrient uptake by Isochrysis aff. galbana (Clone T-ISO) cultured with a low cost alternative to the f/2 medium. Aquac Eng 1999;20(3):135-47.

Vernerey A, Albiol J, Lasseur C, Gòdia F. Scale-up and design of a pilot-plant photobioreactor for the continuous culture of Spirulina platensis. Biotechnol Prog 2001;17(3):431-8.

Vonshak A. Recent advances in microalgal biotechnology. Biotechnol Adv 1990;8(4): 709-27.

Wang B, Lan CQ Horsman M. Closed photobioreactors for production of microalgal biomasses. Biotechnol Adv 2012;30(4):904-12.

Wang Y, Rischer H, Eriksen NT, Wiebe MG. Mixotrophic continuous flow cultivation of Chlorella protothecoides for lipids. Bioresour Technol 2013;144:608-14.

Weger HG, Espie GS. Ferric reduction by iron-limited Chlamydomonas cells interacts with both photosynthesis and respiration. Planta 2000;210(5):775-81.

Weger HG, Middlemiss JK, Petterson CD. Ferric chelate reductase activity as affected by the iron-limited growth rate in four species of unicellular green algae (Chlorophyta). J Phycol 2002;38:513-9.

Weger HG, Matz CJ, Magnus RS, Walker CN, Fink MB, Treble RG. Differences between two gree algae in biological availability of iron bound to strogn chelators. Can J Bot 2006; $84: 400-11$.

Weger HG, Lam J, Wirtz N, Walker CN, Treble RG. High stability ferric chelates result in decreased iron uptake by the green alga Chlorella kessleri owing to decreased ferric reductase activity and chelation of ferrous iron. Botany 2009;87(10):922-31.

Wen X, Geng Y, Li Y. Enhanced lipid production in Chlorella pyrenoidosa by continuous culture. Bioresour Technol 2014;161:297-303. [Jun].

White S, Anandraj A, Bux F. PAM fluorometry as a tool to assess microalgal nutrient stress and monitor cellular neutral lipids. Bioresour Technol 2011;102(2):1675-82.

Wijffels RH, Barbosa MJ, Eppink MHM. Microalgae for the production of bulk chemicals and biofuels. Biofuels, Bioprod Biorefining 2010;4:287-95.

Wijffels RH, Kruse O, Hellingwerf KJ. Potential of industrial biotechnology with cyanobacteria and eukaryotic microalgae. Curr Opin Biotechnol 2013;24(3):405-13.

Wirtz NL, Treble RG, Weger HG. Siderophore-independent iron uptake by ironlimited cells of the cyanobacterium Anabaena Flos-Aquae1. J Phycol 2010; 46(5):947-57.

Wood AM, Everroad RC, Wingard LM. Measuring growth rates in microalgal cultures. In: Andersen RA, editor. Algal culturing techniques. Burlington, USA: Elsevier Academic Press; 2005. p. 269-85.

Yang C, Liu H, Li M, Yu C, Yu G. Treating urine by Spirulina platensis. Acta Astronaut 2008; 63(7-10):1049-54

Zhu Y-H, Jiang J-G. Continuous cultivation of Dunaliella salina in photobioreactor for the production of $\beta$-carotene. Eur Food Res Technol 2008;227(3):953-9.

Zijffers J-WF, Schippers KJ, Zheng K, Janssen M, Tramper J, Wijffels RH. Maximum photosynthetic yield of green microalgae in photobioreactors. Mar Biotechnol (NY) 2010; 12(6):708-18.

Zou N, Zhang C, Cohen ZVI, Richmond A. Production of cell mass and eicosapentaenoic acid (EPA) in ultrahigh cell density cultures of Nannochloropsis sp. (Eustigmatophyceae). Eur J Phycol 2000;35(02):127-33. 